C2016, Elsevier. Licensed under the Creative Commons Attribution-NonCommercialNoDerivatives 4.0 International http://creativecommons.org/about/downloads

cc) 


\title{
Portland-composite and Composite cement concretes made with coarse recycled and recycled glass sand aggregates: Engineering and durability properties
}

\author{
Sevket Can Bostanci ${ }^{\mathrm{a} *}$, Mukesh Limbachiya ${ }^{\mathrm{b}}$, Hsein $\mathrm{Kew}^{\mathrm{c}}$ \\ ${ }^{a}$ Faculty of Engineering, European University of Lefke, North Cyprus, via Mersin 10, Turkey \\ ${ }^{b}$ School of Natural and Built Environments, Kingston University, London KT1 2EE, UK \\ ${ }^{\mathrm{c}}$ School of Natural and Built Environments, Kingston University, London KT1 2EE, UK \\ sevketbostanci@yahoo.com, \\ $\mathrm{T}:$ +90 5338643547
}

\begin{abstract}
Sustainable development approach demands the use of environmentally friendly materials. One possible way to encourage sustainable approach is via use of Portland cement (PC) replacement through use of permitted cement constituents in conformity with BS EN 197-1, to lower carbon footprint, and use of recycled aggregates as permitted within BS 8500, to encourage sustainability. Thus, this research study aimed to produce low carbon and sustainable concrete. For this aim, engineering and durability properties of equal 28-day design strength ( 40 and $50 \mathrm{~N} / \mathrm{mm}^{2}$ ) concretes made with Portland-composite and composite cements, CEM II/B-M and CEM V/A respectively, and partially substituted coarse recycled (RA) and washed recycled glass sand (RGS), $25 \%$ and $15 \%$ respectively, aggregates was investigated. The loss of workability was found to be larger for particularly CEM V/A and recyled aggregate concrete (RAC) mixes. Studies of hardened concrete properties, comprising bulk engineering properties (compressive cube and cylinder strength, flexural strength, drying shrinkage) and durability (initial surface absorption) showed enhanced performance for CEM II/B-M and CEM V/A mixes of equivalent strength natural aggregate concrete mixes (NAC), except resistance to carbonation. However, the use of CEM II/B-M and CEM V cements in RAC mixes slightly reduced the engineering and durability properties compared to corresponding NAC mixes.
\end{abstract}

Keywords: Carbonation, initial surface absorption, drying shrinkage, fly ash, ground granulated blast-furnace slag, silica fume, recycled glass sand, coarse recycled aggregate

\section{Bullet points:}

Use of CEM II/B-M and CEM V/A cements and coarse recycled aggregates and recycled glass sand in concrete production increased the required superplasticizer demand to achieve the similar consistency.

CEM II/B-M cement recycled aggregate concrete mixes indicated either similar or slightly better loss of workability over time compared to corresponding CEM I cement RAC mix. 
The partial substitution of natural coarse and fine aggregates by $25 \%$ coarse recycled and $15 \%$ recycled glass sand aggregates reduced the compressive cube strength of concrete approximately by $10 \%$.

Recycled aggregates concrete mixes showed dramatically lower compressive cylinder strength results compared to conventional natural aggregate concrete mixes.

Drying shrinkage results showed that the contribution of pozzolanic reactions for Portlandslag and composites cement concretes takes place after 14 days.

CEM II/B-M cement mixes indicated lower ISAT-10 values as the design strength class increased.

Carbonation penetration results showed improvement as the design strength increased for the same cement type concrete mixes.

\section{INTRODUCTION}

Reducing the carbon footprint of activities and a more prudent use of natural resources required for concrete production is a significant concern on the grounds of sustainable development. The United Kingdom (UK) construction industry is one of pioneer countries to implement sustainability and thus aiming to encourage prudent use of natural resources, avoid wastage and undue over-designing, reduce use of materials and recycle materials. In this respect, the UK has both international, The Kyoto Protocol, and national, Climate Change Act, targets to reduce the greenhouse gas emissions [1].

Current concrete practices may no longer be considered as sustainable due to PC, the most commonly used cement globally, is a high energy intensive material and its manufacturing requires consumption of raw materials such as clay, gypsum and limestone. In this regard, more environmentally friendly cement main constituents (CMCs) is permitted to be used in concrete production through the European Standard for common cements, BS EN 197-1 [2] to assist industry to achieve its commitments. Nevertheless, the main emphasis on available studies focussed on reducing the embodied $\mathrm{CO}_{2}\left(\mathrm{ECO}_{2}\right)$ emissions of concrete via substituting Portland cement (PC) with other permitted cement types in conformity with BS EN 197-1. Reducing the use of raw materials in the construction industry is another principle of producing sustainable concrete as the natural resources are running low in the world. Thus, Aggregate Levy has come into action by the UK government in order to prevent the use of natural resources and encourage the use of recycled or secondary materials. Primary aggregates, sand and gravel, are the most used materials in construction industry and use of these raw materials cause irreversible effects on the environment such as agricultural losses and rainforest destructions [3]. In the UK, the consumption of primary aggregates is assumed to be around 210 million tonnes whereas $43 \%, 90$ million tonnes, of these are used in the concrete industry [4]. The use of coarse recycled aggregates (RA) in concrete is of significant interest due to its contribution to sustainable development by reducing demand on mineral extraction and minimizing landfill. RA is used in lower grade applications in conformity with BS EN 12620 [5] but it can also be used in higher grade applications when it meets and specifications of BS 8500 [6-7]. The use of recycled and secondary aggregates in 
the UK construction sector has increased over 70 million tones that account for $28 \%$, the highest rate amongst European countries, three times the European average. However, the incorporation of recycled and secondary aggregates used in concrete accounts for $5.3 \%$ [8]. Use of recycled aggregates, where mostly consists of crushed concrete, are also encouraged in codes whereas BS 8500 allows RA to be used in designated concretes up to $20 \%$ except where the specification permits higher proportions to be used. However, there is no generic requirement on the use of recycled fine aggregates. The use of crushed recycled glass sand as a fine aggregate replacement in concrete reduces the overall greenhouse gas emissions and the use of natural aggregates, therefore, improves the sustainability credentials [9]. There is 1.85 million tonnes of glass cullet obtained from waste glass are being collected annually [10]. Having this said, the municipal recycling rate is $34 \%$ for container glass in the UK [11].

Jianyong [12] stated that concrete with $30 \%$ ground granulated blast-furnace slag (GGBS) replacement level and the same superplasticizer (SP) content increased slump value slightly than Portland cement (PC) concrete. Sabet [13] reported that "ball-bearing effect" of fly ash (FA) concrete with FA contents of $10 \%$ and $20 \%$ increased concrete slump and therefore reduced the amount of SP required to reach target slump. Another study by Limbachiya [14] revealed that FA concretes with higher binder content reduced the workability. Gesoglu [15] stated that the relationship between FA and workability loss could be attributed to the presence of FA when used in binary and ternary cements increased viscous characteristics of concretes. Erdem [16] also investigated that silica fume (SF) concretes may require more water as the SF increases due to SF has higher surface area, which this could be compensated by SP utilization. Tu and Chen [17] investigated that RA with higher absorption capacity comparing to natural aggregates have a slight influence on the concrete workability. Limbachiya [18] and Taha [19] stated that use of recycled glass sand (RGS) reduced the workability of the concrete due to lack of fine proportion. Taha [19] also reported homogeneity of the concrete was reduced in the presence of RGS which could be attributed to sharp edges of RGS increased the friction forces in the concrete matrix and thus reduced the consistency.

The use of CMCs has shown to reduce early strength of concrete but to improve long term mechanical performances [19-23]. However, the effect of CMCs on concrete durability is still ambiguous. Moreover, previous researches [24-28] have reported that the use of RA up to $30 \%$ showed slight reduction in mechanical and durability properties of concrete. Researches carried out on RGS concrete mixes have showed that the use of RGS up to $15 \%$ indicated comparable mechanical performances [29].

Previous studies [15, 22, 30] reported FA and GGBS additive ternary blend cement concretes indicated lower shrinkage compared to PC concrete and other ternary blend concretes. Kou [31] stated that increase in the drying shrinkage was proportional to the RA content used. According to Limbachiya [18], the use of RGS up to $20 \%$ was observed not to effect drying shrinkage.

Existing literature [26, 28, 32-33] on the use of CMC reduced carbonation resistance of concrete. Gönen and Yazıcıoğlu [24] investigated ternary blend (PC+FA+SF) concrete had lower carbonation depth which could be attributed to SF addition reduced concrete porosity. Jones and Dhir [34] investigated concretes made with ternary blend cements (PC-FAGGBS) and found that ternary blend mixes had significantly higher carbonation depths 
compared to PC concrete. There is contradicting results on the behaviour of RA on the concrete carbonation resistance. Previous study by Kou [31] indicated that carbonation resistance decreased with the increased RA content. In contrast to that, Soares [35] stated RA did not have significant influence on the carbonation resistance and reported slightly higher results compared to reference mix. Castro and de Brito [36] investigated concretes with RGS contents of $5 \%, 10 \%$ and $20 \%$ by volume had improved carbonation resistance at long terms (56 and 91 days) due to refinement of the pore structure of concrete with the introduction of RGS.

Previous studies [20, 25, 34, 37] revealed that use of CMC reduces the porosity of concrete due to pozzolanic reactions provided by the CMC. Thomas and Setien [38] stated increase in ISAT as RA content increases. Limbachiya [18] investigated an increase in the ISAT when RGS content is beyond $15 \%$ which was believed to due to increase in the porous matrix.

Existing standard, BS 8500, limits the use of RA to be used in structural applications and there is no specification regarding to the use of recycled fine aggregates in concrete production for structural purposes. In addition, there is little information available on the engineering and durability properties of concretes made with CEM II/B-M and CEM V/A cements and recycled coarse and fine aggregates. Thus, this study investigates engineering and durability properties of these concretes associated with the practical applications for the aim of low carbon and sustainable concrete production.

\section{Experimental and testing programme}

\subsection{Materials}

\subsubsection{Cements}

The cement types used were CEM I, CEM II/B-M and CEM V/A conforming to BS EN 197-1. A CEM I, 52,5N PC used for reference mix. Other cement main constituents used were GGBS, FA and SF and blended with PC to produce CEM II/B-M and CEM V/A cements for this study. GGBS was obtained from iron-making production in the UK conforming to BS EN 15167-1 [48]. FA and SF used were conforming to BS EN 450-1 [40] and BS 13263-1 [41] respectively. FA was obtained from Drax coal-fired power station in the UK. SF incorporated was in slurry form including $50 \%$ water and $50 \%$ silica powder. Physical properties and chemical composition of cement constituents used are given in Table 1. 
Table 1. Chemical properties of cementitious constituents

\begin{tabular}{ccccc}
\hline Compound & \multicolumn{4}{c}{ Percentage (\%) } \\
\cline { 2 - 5 } & $\mathrm{PC}$ & $\mathrm{FA}$ & GGBS & $\mathrm{SF}$ \\
\hline $\mathrm{SiO}_{2}$ & 19.77 & 50.4 & 36.76 & 94.84 \\
$\mathrm{Al}_{2} \mathrm{O}_{3}$ & 4.90 & 28 & 13.38 & - \\
$\mathrm{Fe}_{2} \mathrm{O}_{3}$ & 2.33 & 9 & 0.37 & - \\
$\mathrm{CaO}$ & 62.56 & 6 & 39.56 & 0.41 \\
$\mathrm{MgO}$ & 2.64 & 1.50 & 7.33 & - \\
$\mathrm{SO}_{3}$ & 3.08 & 0.40 & 0.08 & 0.32 \\
$\mathrm{~K}_{2} \mathrm{O}$ & 0.66 & 2.50 & 0.54 & 0.88 \\
$\mathrm{Na}_{2} \mathrm{O}$ & 0.17 & 0.90 & 0.32 & 0.26 \\
Loss on ignition & 1.65 & 4.50 & 0.92 & 1.56 \\
Fineness $\left(\mathrm{m}^{2} / \mathrm{kg}\right)$ & 372 & 280 & 501 & 22700 \\
Density $\left(\mathrm{g} / \mathrm{cm}^{3}\right)$ & 3.14 & 2.28 & 2.92 & 1.4 \\
\hline
\end{tabular}

\subsubsection{Aggregates}

Natural river sand and natural uncrushed Thames valley gravel were used as fine and coarse aggregates with maximum nominal sizes of 5 and $20 \mathrm{~mm}$ respectively in conformity with BS EN 12620. The recycled coarse aggregate and recycled washed glass sand (RGS), meeting the requirements of BS EN 12620, were used in RAC mixes to substitute natural aggregates. RA was graded $20-5 \mathrm{~mm}$ aggregates and observed to be irregular shaped compared to natural coarse aggregates. Recycled washed glass sand (RGS) with maximum nominal size of $5 \mathrm{~mm}$ was observed to be coarser than natural sand. The physical and mechanical properties of natural and recycled aggregates used are given in Table 2 and Figure 1.

Table 2. Physical and mechanical properties of aggregates used

\begin{tabular}{lcccc}
\hline Properties & \multicolumn{4}{c}{ Nype of aggregates } \\
& Sand & Gravel & Glass sand & Gravel \\
\cline { 2 - 5 } & & & & \\
\hline Physical $(B S E N ~ 1097$, part 6) & 1.61 & 1.49 & 1.35 & 1.37 \\
Unit weight $\left(\mathrm{g} / \mathrm{m}^{3}\right.$ ) & 41.7 & 39.9 & 42.3 & 43.2 \\
Percentage of voids (\%) & 2.78 & 2.59 & 2.38 & 2.57 \\
Apparent density $\left(\mathrm{g} / \mathrm{m}^{3}\right)$ & 0.17 & 1.69 & 0.66 & 2.57 \\
Water absorption capacity (\%) & 2.76 & 2.52 & 2.36 & 2.47 \\
Specific gravity & 2.62 & 3.31 & 3.10 & 3.54 \\
Fineness modulus & & & & \\
\hline Mechanical (BS 812, parts 110-112) & - & 15.7 & - & 18.0 \\
Aggregate crushing value (\% ACV) & - & 10.7 & - & 6.5 \\
Aggregate impact value (\% AIV) & - & & & \\
\hline${ }^{*}$ Mechanical properties were measured on 10-14 mm test samples &
\end{tabular}




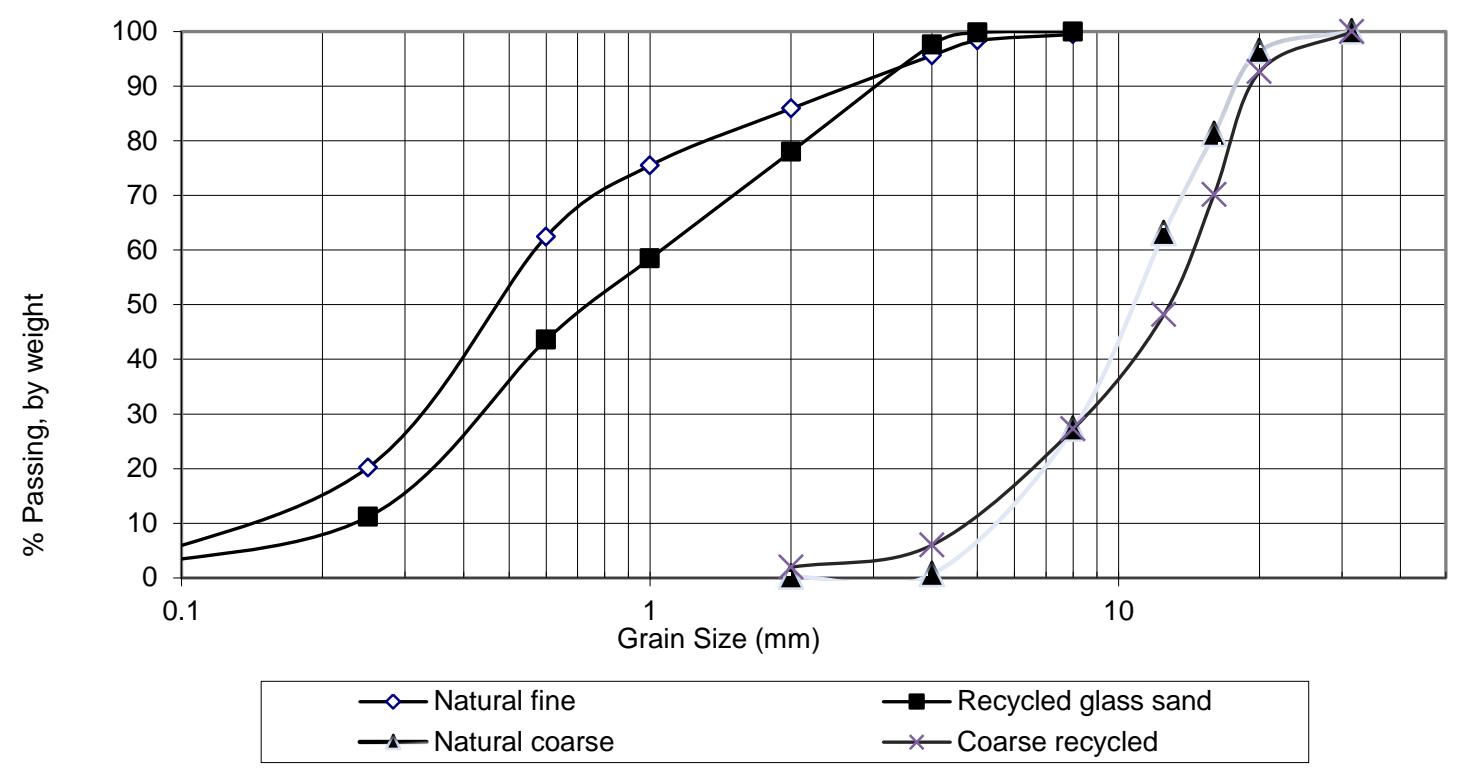

Figure 1. Particle size distribution of natural and recycled aggregates used in this study

\subsubsection{Admixture}

Water reducer liquid SP, ADVA 655, obtained from Grace Construction Products Limited based on polycarboxylate molecules was used to provide slump retention especially for mixes with lower w/c ratios and high early and late strength development. Its use was in conformity with BS EN 934-2:2009+A1:2012 [42].The dosage required was arranged during the optimisation of the mixes dependent upon $\mathrm{w} / \mathrm{c}$ ratio and the amount and nature of cementitious materials used.

\subsubsection{Water}

Standard tap water was used during the concrete production for all mixes. In addition to that, de-ionised water was used to carry out ISAT for the concrete durability.

\subsection{Mix proportions and concrete mix design}

Conventional BRE mix design method [43] was used to produce trial mixes for a given design strength. Mixes were designed to achieve workability between $60-180 \mathrm{~mm}$ in conformity with BRE mix design document and S3 consistency class in accordance with BS EN 206-1 [44]. The 28-day cube strengths sought were 40 and $50 \mathrm{~N} / \mathrm{mm}^{2}$. The free water contents of these mixes were modified according to type of the cementitious constituents used. To achieve equivalent 28-day cube strength as CEM I concrete, the w/c ratios and total cementitious contents were altered depending upon the relationship between the 
compressive cube strength and the $\mathrm{w} / \mathrm{c}$ ratios of trial mixes. Detailed summary of mix proportions used are given in Table 3 and Table 4 . It is noteworthy to mention that SF values given is in slurry form, thus half of the SF used was deducted from the free water content. When SF used, free water/cement ratio was determined by adding free water content and half of the SF used and divided by cementitious content including binders but half of the SF used.

The initial mix was a control mix with PC only specified as CEM I and a Portlandcomposite cement mix was CEM II/B-M (65\%PC/30\%GGBS/5\%SF). Additionally, a composite cement mix stated as CEM V/A (40\%PC-30\%GGBS-30\%FA). At first, these cements were used to produce natural aggregate concrete (NAC) mixes. Having NAC mixes established, optimisation of concrete mixes was carried out to determine the replacement ratios of recycled aggregates, both recycled glass sand and recycled coarse aggregate, for the optimum strength concrete for a margin of no more than $10 \%$ strength loss compared to corresponding NAC mixes. The replacement ratios were determined as $25 \%$ and $15 \%$, on mass basis, for RA and RGS as coarse and fine aggregates respectively for the production of recycled aggregate concrete (RAC) mixes. The application of both RGS and RA were carried out in saturated surface dry state and water content of the concrete mixes were compensated prior to mixing considering the water absorption capacities and moisture content of RA and RGS.

Table 3. Mix proportions for 28-day 40 and $50 \mathrm{~N} / \mathrm{mm}^{2}$ design strength NAC mixes

\begin{tabular}{|c|c|c|c|c|c|c|c|c|c|c|c|}
\hline \multirow{4}{*}{$\begin{array}{l}\text { Design } \\
\text { strength }\end{array}$} & \multirow[t]{4}{*}{ Cements } & \multicolumn{9}{|c|}{ Mix proportions $\left(\mathrm{kg} / \mathrm{m}^{3}\right)$} & \multirow{4}{*}{$\begin{array}{c}\text { Free } \\
\text { water/cement } \\
\text { ratio }\end{array}$} \\
\hline & & \multirow[t]{3}{*}{ Water } & \multicolumn{4}{|c|}{ Cementitious constituents } & \multicolumn{4}{|c|}{ Aggregates } & \\
\hline & & & \multirow[t]{2}{*}{ PC } & \multirow[t]{2}{*}{ FA } & \multirow[t]{2}{*}{ GGBS } & \multirow[t]{2}{*}{ SF } & \multicolumn{2}{|c|}{ Gravel } & \multicolumn{2}{|c|}{ Sand } & \\
\hline & & & & & & & NA & RA & NS & RGS & \\
\hline \multirow{3}{*}{$40 \mathrm{~N} / \mathrm{mm}^{2}$} & CEM I & 195 & 385 & - & - & - & 1120 & - & 645 & - & 0.51 \\
\hline & CEM II/B-M & 175 & 210 & - & 95 & 30 & 1120 & - & 720 & - & 0.59 \\
\hline & CEM V/A & 170 & 165 & 120 & 120 & - & 1135 & - & 650 & - & 0.41 \\
\hline \multirow{3}{*}{$50 \mathrm{~N} / \mathrm{mm}^{2}$} & CEM I & 195 & 460 & - & - & - & 1085 & - & 620 & - & 0.41 \\
\hline & CEM II/B-M & 175 & 270 & - & 125 & 40 & 1085 & - & 660 & - & 0.47 \\
\hline & CEM V/A & 170 & 175 & 130 & 130 & - & 1085 & - & 670 & - & 0.39 \\
\hline
\end{tabular}

Table 4. Mix proportions for 28-day 40 and $50 \mathrm{~N} / \mathrm{mm}^{2}$ design strength RAC mixes

\begin{tabular}{|c|c|c|c|c|c|c|c|c|c|c|c|}
\hline \multirow{4}{*}{$\begin{array}{l}\text { Design } \\
\text { strength }\end{array}$} & \multirow[t]{4}{*}{ Cements } & \multicolumn{9}{|c|}{ Mix proportions $\left(\mathrm{kg} / \mathrm{m}^{3}\right)$} & \multirow{4}{*}{$\begin{array}{c}\text { Free } \\
\text { water/cement } \\
\text { ratio }\end{array}$} \\
\hline & & \multirow[t]{3}{*}{ Water } & \multicolumn{4}{|c|}{ Cementitious constituents } & \multicolumn{4}{|c|}{ Aggregates } & \\
\hline & & & \multirow[t]{2}{*}{ PC } & \multirow[t]{2}{*}{ FA } & \multirow[t]{2}{*}{ GGBS } & \multirow[t]{2}{*}{ SF } & \multicolumn{2}{|c|}{ Gravel } & \multicolumn{2}{|c|}{ Sand } & \\
\hline & & & & & & & NA & RA & NS & RGS & \\
\hline \multirow{3}{*}{$40 \mathrm{~N} / \mathrm{mm}^{2}$} & CEM I & 195 & 385 & - & - & - & 840 & 280 & 550 & 95 & 0.51 \\
\hline & CEM II/B-M & 175 & 210 & - & 95 & 30 & 840 & 280 & 610 & 110 & 0.59 \\
\hline & CEM V/A & 170 & 165 & 120 & 120 & - & 850 & 285 & 575 & 105 & 0.41 \\
\hline \multirow{3}{*}{$50 \mathrm{~N} / \mathrm{mm}^{2}$} & CEM I & 195 & 460 & - & - & - & 815 & 270 & 515 & 90 & 0.41 \\
\hline & CEM II/B-M & 175 & 270 & - & 125 & 40 & 815 & 270 & 555 & 100 & 0.47 \\
\hline & CEM V/A & 170 & 175 & 130 & 130 & - & 815 & 270 & 570 & 100 & 0.39 \\
\hline
\end{tabular}




\subsection{Test procedures}

Concrete production and testing was carried out in accordance with BS EN 12350:2000 Parts 1 and 2. After concrete production, initial slump was recorded, and then slump loss was examined through conducting compacting factor test with 30 minutes intervals up to 150 minutes. Mix samples were covered under polythene sheets for 24 hours after casting under moist condition, prior to testing or exposure to $20{ }^{\circ} \mathrm{C}$ water curing condition in conformity with BS EN 12390-2. Engineering properties investigated included compressive and flexural strengths and drying shrinkage. $100 \mathrm{~mm}$ cubes were cast to investigate compressive strength development of concrete mixes conforming to BS EN 12390-3 [45]. Compressive cylinder strengths were determined through testing $150 \mathrm{~mm}$ diameter and $300 \mathrm{~mm}$ high cylinder specimens. Flexural strengths were obtained under four-point loading with specimen dimensions of $100 \mathrm{~mm} \times 100 \mathrm{~mm} \times 500 \mathrm{~mm}$ in accordance with BS EN 12390-5. Drying shrinkage was measured on $75 \mathrm{~mm} \times 75 \mathrm{~mm} \times 280 \mathrm{~mm}$ prism specimens. The samples were cured under water for the first 7 days and then stored in drying environment $\left(22^{\circ} \mathrm{C}\right.$ and $55 \% \mathrm{RH}$ ) in conformity with BS ISO 1920-8 [46]. Drying shrinkage values were recorded using stainless strain gauge pins fixed through both edges up to 112 days. In addition, initial surface absorption test and carbonation resistance were investigated to establish durability performance of concrete mixes. 3 samples were tested and averaged for different types of tests at given test ages.

\subsubsection{Permeation property}

Measuring the porosity of the concrete by the rate of the water penetrating into concrete is one of the indicators to assess the durability of concrete. Near surface absorption of concrete was determined using the initial surface absorption test (ISAT), as described in BS 1881-208 [47]. $150 \mathrm{~mm}$ cube samples were cast and cured in $20^{\circ} \mathrm{C}$ water for 28 days, then followed by pre-conditioning through oven drying at $105^{\circ} \mathrm{C}$ to constant mass prior to test. The contact surface area was sealed to prevent any leakage during the test while testing and evaluation of the volume flow is obtained by measuring the length of flow along the capillary tube with a known dimension. ISAT values were determined after ten minutes (ISAT-10) in $\mathrm{ml} / \mathrm{m}^{2} /$ second.

The ISAT-10 value of $50 \times 10^{-2} \mathrm{ml} / \mathrm{m}^{2} / \mathrm{sec}$ is mostly assumed as high whilst below $25 \times 10^{-2}$ $\mathrm{ml} / \mathrm{m}^{2} / \mathrm{sec}$ is assumed as low [48]. Moreover, $\mathrm{N}$-value which indicates rate of decay in the absorption with time are also provided in accordance with the ISAT values of concretes.

\subsubsection{Carbonation penetration}

The carbonation of penetration of concretes was assessed using $100 \mathrm{~mm}$ cubes that were cured in CU1 conditions and stored in ambient conditions for at least 14 days to air dry. The samples were exposed to an enriched environment of 3.5 to $4.0 \% \mathrm{CO}_{2}$ concentration in a chamber at standard $20{ }^{\circ} \mathrm{C}$ and $60 \%$ relative humidity as described in BS 1881-210 [49]. The top and bottom surfaces and two opposite sides of the concrete samples were coated with epoxy based paint to allow $\mathrm{CO}_{2}$ to penetrate only through the sides and exposed to $\mathrm{CO}_{2}$ 
in 13, 26 and 52 weeks. Samples of thicknesses of not less than $10 \mathrm{~mm}$ were cut with watercooled diamond saw and carbonation depth was measured by spraying phenolphthalein indicator solution $(1 \mathrm{gr}$ phenolphthalein indicator in a solution $70 \mathrm{ml}$ ethanol and $30 \mathrm{ml}$ demineralised water). After the indicator solution is sprayed, carbonated sections with $\mathrm{pH}$ value of less than 9.2 remains colourless whereas in the non-carbonated section, the colour turns pink due to its alkalinity. The carbonation depth indicated by the boundary where the concrete turned pink. Three or four readings from each side were recorded and averaged in order to determine the carbonation depth. The depths behind the coarser aggregates were ignored.

\section{Results and discussions}

\subsection{Fresh properties}

Fresh properties of concrete mixes were established through slump test and loss of workability over time. Slump test of concretes was carried out immediately after the mixing. The slump test results are given in Table 6. These values are not an indication as concretes having different admixture contents were designed to achieve S3 consistency class in accordance with BS EN 206-1. The admixtures required to achieve the target slump values were 300, 1250, 2000 and 750, 1350 and $2500 \mathrm{ml} / \mathrm{m}^{3}$ for CEM I, CEM II/B-M and CEM V/A cement 40 and $50 \mathrm{~N} / \mathrm{mm}^{2}$ design strength concrete mixes respectively. Whilst, the admixture contents required for target slump values for RAC mixes were 1250, 1650, 2600 and 1600, 1900 and $3300 \mathrm{ml} / \mathrm{m}^{3}$ for CEM I, CEM II/B-M and CEM V cement mixes respectively. Loss of workability over time of equal design strength NAC and RAC mixes are also given in Figures 2 and 3 respectively.

In general, CEM I mixes had higher free water content and higher $w / c$ ratios, thus required the lowest SP content amongst concrete mixes. This can be also due to having only PC presence in the cementitous system. In parallel with this, it was also observed that SP demand required increased with the increased the replacement level of CMC in CEM II/B-M and CEM V/A mixes. This is in agreement with the previous studies [15, 30, 33-34, 50]. The effect of w/c on SP demand was more obvious for CEM V/A mixes compared to CEM II/B-M mixes. In brief, RAC mixes required higher SP demand in order to achieve the desired slump compared to NAC mixes. This could be attributed to higher WA of both RA and RGS required higher water content and free water content was insufficient to cover higher WA of recycled aggregate as stated by $\mathrm{Tu}$ [26]. In addition, the reduction in consistency is believed to be lack of fines which required more SP.

The results showed that compacting factor values decreased with the increasing design strength which is thought to be due to lower w/c ratios of $50 \mathrm{~N} / \mathrm{mm}^{2}$ design strength concretes compared to $40 \mathrm{~N} / \mathrm{mm}^{2}$ design strength concretes. This reduction is in agreement with the previous study by McCarthy and Dhir [51]. However, it was observed that CEM II/B$\mathrm{M}$ cement mixes indicated similar results at some point of the test. This could be due to better dispersion and smooth and dense surface characteristics of GGBS which absorbs 
less water over time [20]. $40 \mathrm{~N} / \mathrm{mm}^{2}$ design strength CEM II/B-M cement NAC mixes with the highest $\mathrm{w} / \mathrm{c}$ ratio provided similar results as corresponding CEM I concrete had higher $\mathrm{w} / \mathrm{c}$ ratio amongst concretes. However, $50 \mathrm{~N} / \mathrm{mm}^{2}$ design strength CEM II/B-M cement NAC mix showed lower performance with the same w/c ratio as CEM I concrete for NAC mixes. This can be attributed to extremely fine particle size of SF resulted in increased adsorption and thus increased water demand in order to maintain the fluidity of the concrete mix [24, 52]. This is in line with previous researches [24, 52] that fine particle size of SF increases adsorption and requires more water to maintain the fluidity of concrete. Unlike NAC mixes, CEM II/B-M cement RAC mix indicated higher CF values over time for $40 \mathrm{~N} / \mathrm{mm}^{2}$ design strength concretes and similar CF values for $50 \mathrm{~N} / \mathrm{mm}^{2}$ design strength concretes. This can be attributed to smooth texture of GGBS and higher SP demand, in comparison to NAC mixes and CEM I cement RAC mixes. This then dissipated cohesive properties of SF concrete by dispersing the cement and SF particles through its adsorption and electric repulsion mechanism which increased the fluidity of concretes as stated previously by Johari [20]. In contrast with CEM II/B mixes, the effect of w/c was obvious on CEM V mixes. CEM V/A cement NAC mixes demonstrated lower compacting factor values in comparison to CEM I and CEM II/B-M cement NAC mixes. This is believed to be due to higher total cementitious content and lower water content, thereby lower w/c ratio, of CEM V cement concretes than other mixes. However, advantageous smooth characteristics of GGBS were observed to be mitigated by the FA presence and reduced the fluidity effect of GGBS in CEM V/A cement mixes which is in agreement with the previous study by Thomas [53]. Similar trend as NAC mixes were observed for CEM V/A cement RAC mixes.

In general, it was observed that RAC mixes had higher loss of workability in comparison to NAC mixes. This is believed to be higher WA of both porous RGS and RA compared to natural aggregates has lead to higher loss of workability due to increased water demand which is in agreement with previous studies [19-26].

Table 5 - Workability results for NAC mixes

\begin{tabular}{|c|c|c|c|c|c|}
\hline $\begin{array}{l}\text { 28-day } \\
\text { design } \\
\text { strength } \\
\left(\mathrm{N} / \mathrm{mm}_{2}\right)\end{array}$ & Cement & w/c ratio & $\begin{array}{c}\text { Free water } \\
\text { content } \\
\left(\mathrm{kg} / \mathrm{m}_{3}\right)\end{array}$ & $\begin{array}{l}\text { SP } \\
(\mathrm{ml})\end{array}$ & $\begin{array}{c}\text { Slump } \\
\text { value }(\mathrm{mm})\end{array}$ \\
\hline \multirow{3}{*}{40} & $\begin{array}{l}\text { CEM I } \\
\text { (100PC) }\end{array}$ & 0.51 & 195 & 300 & 125 \\
\hline & $\begin{array}{c}\text { CEM II/B-M } \\
\text { (65PC/30FA/5SF) }\end{array}$ & 0.59 & 175 & 1250 & 120 \\
\hline & $\begin{array}{c}\text { CEM V/A } \\
\text { (40PC/30GGBS/30FA) }\end{array}$ & 0.40 & 170 & 2000 & 150 \\
\hline \multirow{3}{*}{50} & $\begin{array}{l}\text { CEM I } \\
(100 P C)\end{array}$ & 0.44 & 195 & 750 & 100 \\
\hline & CEM II/B-M & 0.46 & 175 & 1350 & 100 \\
\hline & $\begin{array}{c}\text { CEM V/A } \\
\text { (40PC/30GGBS/30FA) }\end{array}$ & 0.38 & 170 & 2500 & 140 \\
\hline
\end{tabular}


Table 6 - Workability results for RAC mixes

\begin{tabular}{|c|c|c|c|c|c|}
\hline $\begin{array}{l}\text { 28-day } \\
\text { design } \\
\text { strength } \\
\left(\mathrm{N} / \mathrm{mm}_{2}\right)\end{array}$ & Cement & w/c ratio & $\begin{array}{c}\text { Free water } \\
\text { content } \\
\left(\mathrm{kg} / \mathrm{m}_{3}\right)\end{array}$ & $\begin{array}{l}\text { SP } \\
(\mathrm{ml})\end{array}$ & $\begin{array}{c}\text { Slump } \\
\text { value }(\mathrm{mm})\end{array}$ \\
\hline \multirow{3}{*}{ (18тाпाг) } & $\begin{array}{l}\text { CEM I } \\
(100 P C)\end{array}$ & 0.51 & 195 & 1250 & 125 \\
\hline & CEM II/B-M & 0.59 & 175 & 1650 & 135 \\
\hline & $\begin{array}{c}\text { (65PC/30FA VSF) } \\
\text { CEM V/A } \\
\text { (40PC/30GGBS/30FA) }\end{array}$ & 0.40 & 170 & 2600 & 85 \\
\hline \multirow{3}{*}{50} & $\begin{array}{l}\text { CEM I } \\
(100 P C)\end{array}$ & 0.44 & 195 & 1950 & 120 \\
\hline & CEM II/B-M & 0.46 & 175 & 1250 & 120 \\
\hline & $\begin{array}{c}\text { CEM V/A } \\
\text { (40PC/30GGBS/30FA) }\end{array}$ & 0.38 & 170 & 2000 & 150 \\
\hline
\end{tabular}

28-day design strength: $40 \mathrm{~N} / \mathrm{mm}^{2}$

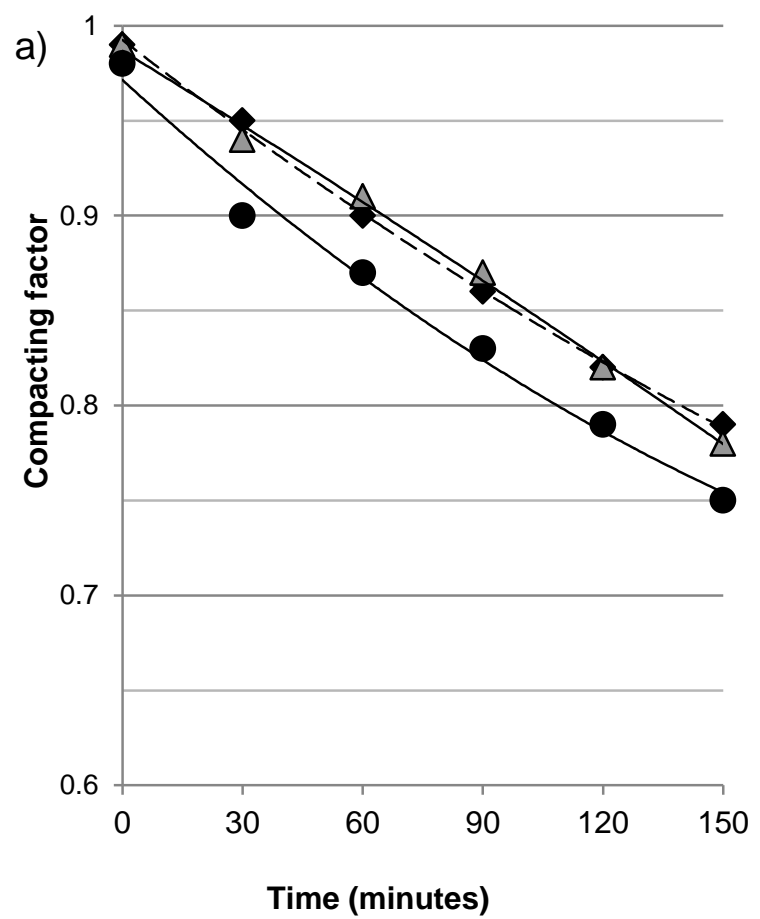

28-day design strength: $50 \mathrm{~N} / \mathrm{mm}^{2}$

b)
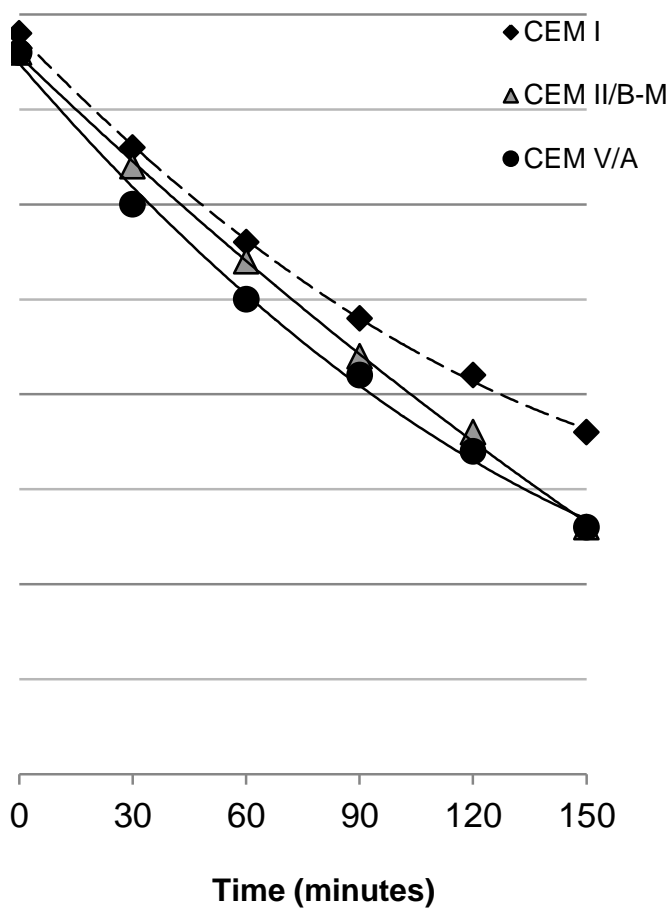

Figure 2. Loss of workability over time of equal design strength NAC mixes 


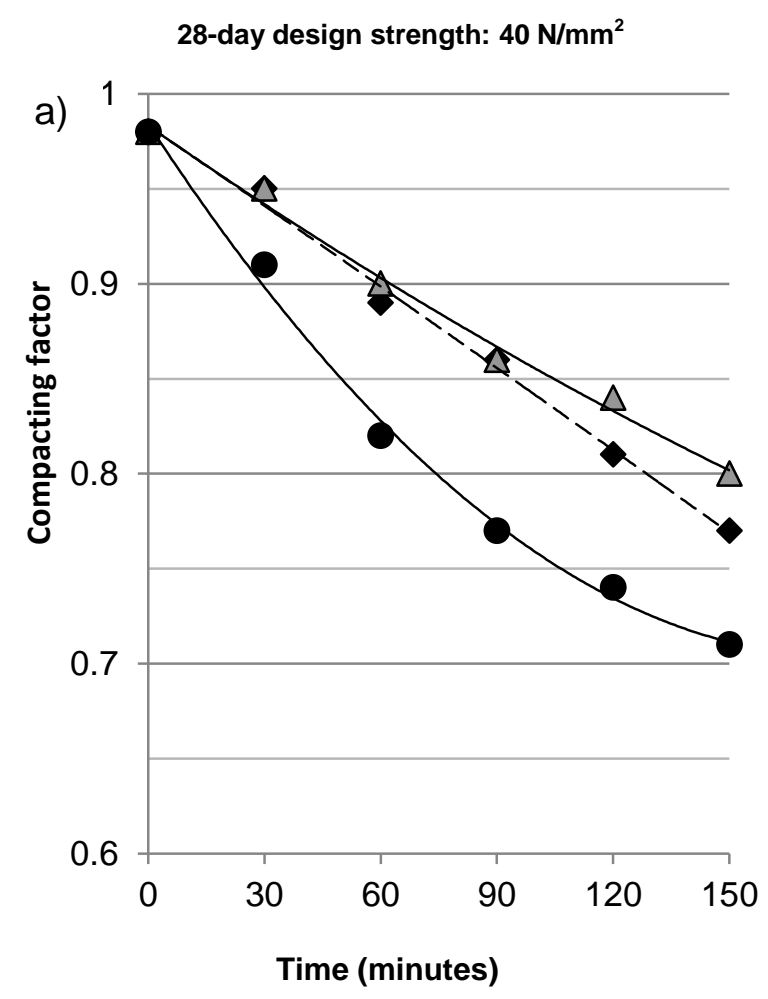

28-day design strength: $50 \mathrm{~N} / \mathrm{mm}^{2}$

b)

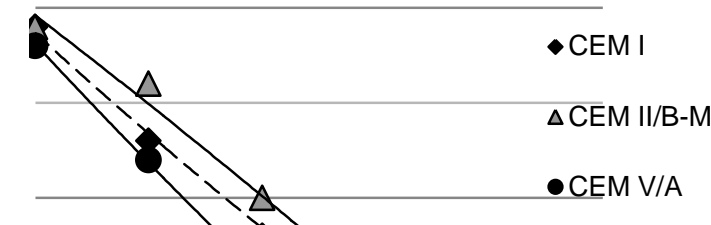

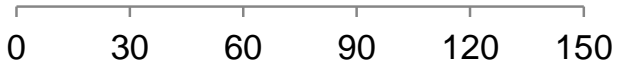

Time (minutes)

Figure 3. Loss of workability over time of equal design strength RAC mixes

\subsection{Hardened Properties}

\subsubsection{Mechanical/Engineering properties}

Concrete compressive and flexural strengths are of great importance as these properties are utilised to specify structural concrete members within design parameters. Addition to these, drying shrinkage is another engineering property that could be considered as important parameter in structural concrete members. These properties are influenced by the type and proportioning of the constituents and type of the aggregates used in concrete production.

\subsubsection{Strength properties}

\section{Compressive cube strength}

The compressive cube strength development results are given in Figures 4 and 5 for 40 and $50 \mathrm{~N} / \mathrm{mm}^{2}$ design strength NAC and RAC mixes respectively. It can be seen from the results that CEM I mixes developed higher early strength compared to CEM II/B-M and CEM V/A for both NAC and RAC mixes. On the contrary, CEM II/B-M and CEM V/A mixes indicated lower early strengths than CEM I mixes. The reduction in strength is proportional with the replacement level of $\mathrm{PC}$. This can be attributed to higher Calcium oxide $(\mathrm{CaO})$ content in $\mathrm{PC}$ composition that played significant role in the development of early strength. Replacing PC with CMCs resulted in lowering $\mathrm{CaO}$ content and thus provided lower early strength. This is believed to be due to lower surface area of CMCs do not contribute to strength development 
at initial stages. It is worth mentioning that $w / c$ ratio did not have any influence on the early strength loss which is due to that concrete mixes were cast with various SP contents. This is in contrast with previous researches carried out by Qiang [54] and Teng [55].

For NAC and RAC mixes, strength development between 28 and 365 days for CEM I mixes were observed to be lower than CEM II/B-M and CEM V/A mixes. Even though, CEM II/B-M and CEM V/A mixes indicated similar compressive strength at 28 days for both NAC and RAC mixes. In contrast with some researches [53, 56], the results showed that the contribution of the pozzolanic reactions due to CMCs presence took place at pre-28 days. It is also believed to be due to hydration of GGBS and FA is slower than PC, thus, pozzolanic reaction through CMCs and cement paste necessitates longer curing age in order to contribute to strength development. The improvement was more evident with the prolonged curing period. At post-28 days, CEM II/B-M and CEM V/A mixes provided either similar or higher strength results compared to conventional CEM I mixes except $40 \mathrm{~N} / \mathrm{mm}^{2}$ design strength CEM II/B-M cement RAC mix which indicated slightly lower strengths than 40 $\mathrm{N} / \mathrm{mm}^{2}$ design strength CEM I cement RAC mix. This could be due to CEM II/B-M mix had the lowest total cementitious amongst all mixes and depletion of SF over time in concrete matrix [32]. However, the reduction in early strength for CEM V/A mixes was much more than CEM II/B-M mixes. In addition, higher strength development of CEM II/B-M in comparison to CEM V/A mixes at pre-28 days could also be explained by both physical and chemical characteristics of SF which converted $\mathrm{CH}$ to $\mathrm{CSH}$ with its extreme fineness. This in line with previous researches $[32,56]$. Moreover, the effect of pozzolanic reaction was more apparent in CEM V/A mixes as comparable or slightly higher results were reported at latter ages. The strength development between 28 and 365 days for CEM V/A mixes was higher than CEM I and CEM II/B mixes for both NAC and RAC mixes. This supports the fact stated by Bernal and Provis [23] that higher binder content could provide higher compressive strength. The improvement in CMCs present mixes could be attributed to the finer characteristics of CMCs which resulted in the formation of a dense structure. Also, the use of CMCs provided extra CSH (Calcium silicate hydrate) gel by reacting with $\mathrm{CH}$ (Calcium hydroxide) that resulted in increase in the strength at post 28 days. This is in agreement with previous researches carried out [20, 23].

It was observed that recycled aggregates substituon with natural aggregates with particular replacement levels achieved slightly reduced strengths at all ages. However, the effect of both RA and RGS, solely, is not obvious. The reduction in compressive strength could be dependant upon the several factors. Initially, the incorporation of RA with lower density leads to decrease concrete density and concrete strength. In addition, the use of RGS and RA increased the fineness modulus of the aggregates. This is thought to decrease the concrete density and resulted decrease in the bond strength between recycled aggregates and the cement paste. Also, the inclusion of RGS is believed to form a weak adhesion between the interface between the RGS and the cement pastes as stated previously by Kou [21] and Ling [57]. Strength loss could also be attributed to lack of fines due to coarser particle sizes of RGS which diminished the filler effect of fine aggregates and resulted in more porous matrix. On the other hand, insufficient water content as a result of higher WA capacity of RA is believed to lead to deficiency in the hydration of cement paste which reduced the compressive strength. In addition, strength loss can also be attributed to weaker characteristics of RA due to higher porosity reduced the strength of ITZ which resulted in reduction in concrete strength. 
28-day design strength: $40 \mathrm{~N} / \mathrm{mm}^{2}$
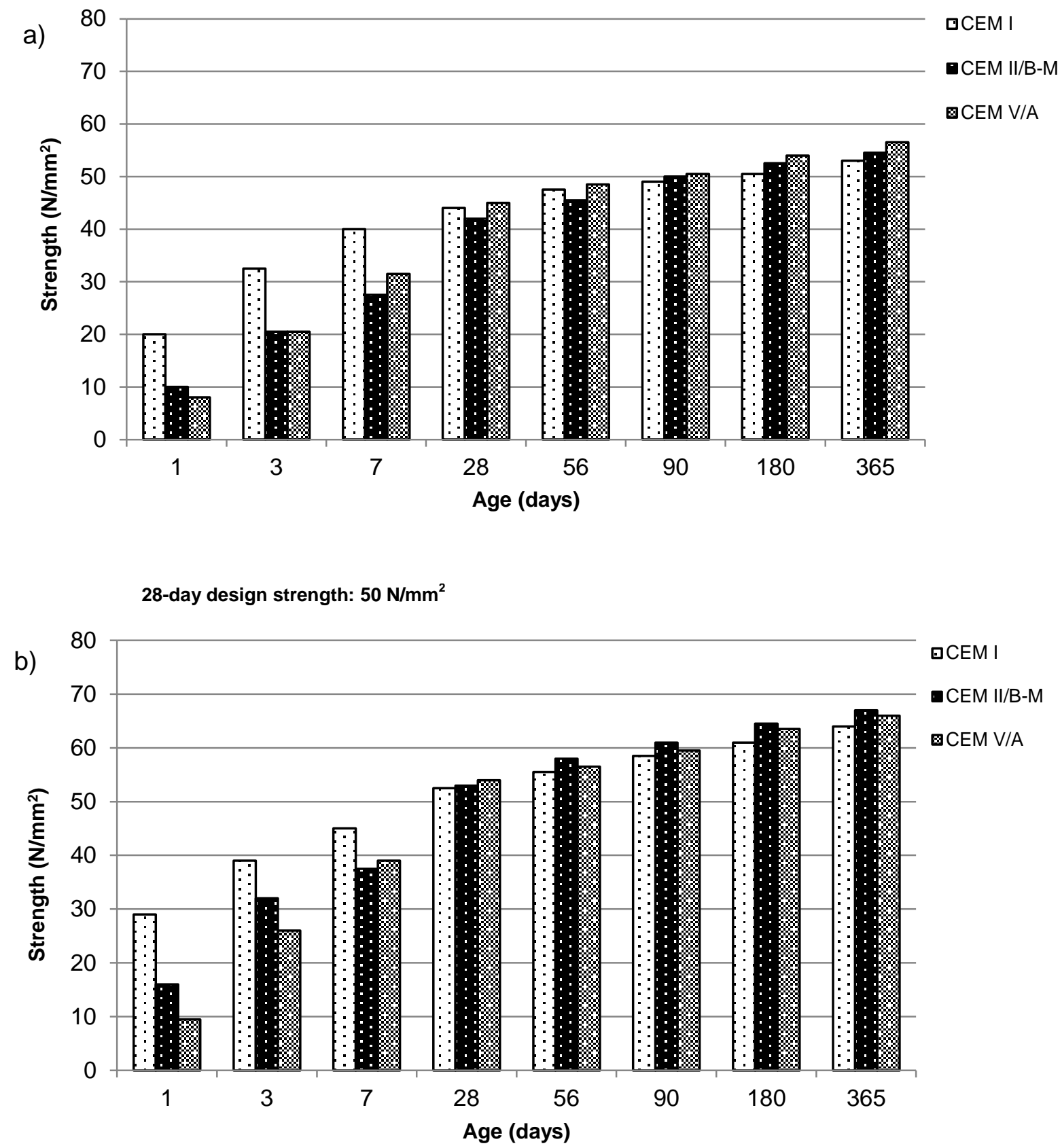

Figure 4. Compressive cube strength development of equal design strength NAC mixes 

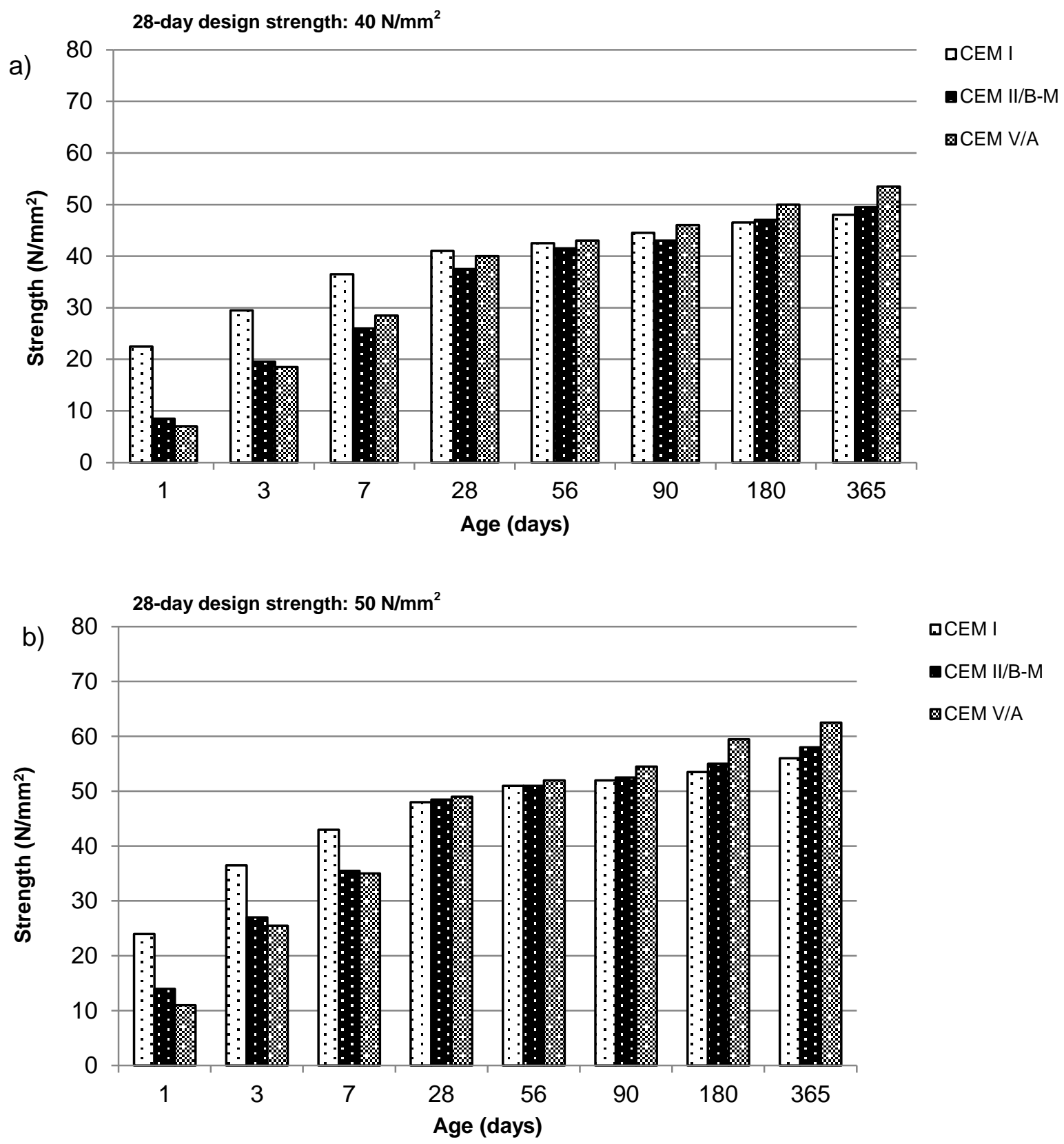

Figure 5. Compressive cube strength development of equal design strength RAC mixes

\section{Compressive cylinder strength}

The relationship between cylinder and cube compressive strength $\left(f_{c, \text { cyy }} / f_{c, \text { cube }}\right)$ is of current interest as design to BS EN 1992 is based on compressive cylinder and cube strengths is generally adopted for conformity evaluation and factor of 0.8 is adopted in BS EN 206. On the other hand, previous studies [58-59] indicated $f_{c, c y} / f_{c, \text { cube }}$ ratios of $0.58-0.94$. In the light of this, the relationship between the compressive cylinder and cube strengths at different ages were evaluated. The correlation of compressive cylinder and cube strengths including 28, 56 and 91 days are given in Figures 6(a) and 6(b) for NAC and RAC mixes respectively. Also, the results for $f_{c, c y} / f_{c, c u b e}$ ratios for NAC and RAC are given in Figures $7(a)$ and $7(b)$ and 
Figures 8(a) and $8(b)$ respectively for both design strength concretes. In addition to these, the comparison between the NAC and RAC mixes are given in Figure 9.

For NAC mixes, the relationship between compressive cylinder and cube strengths showed a strong correlation of $R^{2}=0.97$ and $R^{2}=0.98$ for CEM I and CEM II/B-M mixes respectively. CEM V/A cement NAC mixes indicated lower correlation $\left(R^{2}=0.94\right)$ than other NAC mixes. Moreover, $\mathrm{f}_{\mathrm{c}, \mathrm{cy}} / \mathrm{f}_{\mathrm{c}, \text { cube }}$ ratios for CEM II/B-M and CEM V/A mixes were comparable to CEM I mixes but lower than design factor 0.8 except $40 \mathrm{~N} / \mathrm{mm}^{2}$ design strength CEM II/B-M mix at 56 days. Higher $f_{c, c y l} / f_{c, c u b e}$ ratios of CEM II/B-M mixes can be explained by the presence of extremely fine SF particles improved the matrix between the aggregates and the cement paste. Even though, $f_{c, c y} / f_{c, c u b e}$ ratios for NAC mixes were in the range specified by the previous studies [58-59].

The results for $R A C$ mixes indicated remarkably lower correlation $\left(R^{2}=0.11\right)$ for CEM I mixes. $40 \mathrm{~N} / \mathrm{mm}^{2}$ design strength CEM I mix showed superior performance than other mixes which also reflected to higher $f_{c, c y} / f_{c, c u b e}$ ratios at all ages ranged over 0.6 whilst $50 \mathrm{~N} / \mathrm{mm}^{2}$ design strength concretes indicated around 0.5. This lead to the low correlation for CEM I mixes. The $\mathrm{f}_{c, \text { cy }} / \mathrm{f}_{\mathrm{c}, \text { cube }}$ ratios was found to be lower than design factor of 0.8 but within the range specified by the previous researches [58-59]. However, there was a strong correlation $\left(R^{2}=0.94\right)$ between compressive cylinder and cube strengths observed for CEM II/B mixes. For $f_{c, c y} / f_{c}$,cube ratios, there are two different trends observed for different strength classes. For instance, it was observed that $40 \mathrm{~N} / \mathrm{mm}^{2}$ design strength CEM II/B-M mixes achieved lower ratios than CEM I mixes at all ages ranged between 0.48 and 0.53 which is lower than the range observed previously. In contrast with that, $50 \mathrm{~N} / \mathrm{mm}^{2}$ design strength CEM II/B-M mix indicated superior results at all ages compared to CEM I mix with $f_{c, c y l} / f_{c, c u b e}$ ratios between 0.59 and 0.70 . Nonetheless, $\mathrm{f}_{\mathrm{c}, \mathrm{cy}} / \mathrm{f}_{\mathrm{c}, \text { cube }}$ ratios for CEM II/B mixes were lower than design factor 0.8 but within the range stated. CEM $\vee$ mixes also showed a good correlation $\left(R^{2}=0.98\right)$ between compressive cylinder and cube strengths. Similar to relationship between CEM II/B-M and CEM I mixes, different trends were observed for different design strength concretes for CEM V mixes. Lower results were reported for $40 \mathrm{~N} / \mathrm{mm}^{2}$ design strength concretes whilst slightly higher strengths were recorded for $50 \mathrm{~N} / \mathrm{mm}^{2}$ design strength concretes. It can be seen from the results that $f_{c, c y} / f_{c, \text { cube }}$ ratios were significantly lower than design factor 0.8 and the range observed by previous research with ranging between 0.47 0.49 and $0.48-0.50$ for 40 and $50 \mathrm{~N} / \mathrm{mm}^{2}$ design strength concrete mixes respectively.

The use of recycled aggregates in CEM I, CEM II/B-M and CEM V/A mixes reduced the compressive cylinder strength dramatically in comparison to corresponding NAC mixes. This significant reduction could be attributed to inherent characteristics of both RA and RGS that lead to formation of weaker bond in the concrete interfacial transition zone (ITZ) between the cement paste and the aggregates. In parallel with that significant reduction in $f_{c, \text { cyl }} / f_{c, \text { cube }}$ was observed for RAC mixes. The $f_{c, c y} / f_{c, c u b e}$ ratios was observed to be between 0.65 and 0.80 for NAC mixes whilst lower $f_{c, c y} / f_{c, \text { cube }}$ ratios were reported for RAC mixes ranging between 0.47 and 0.62 . 
a)

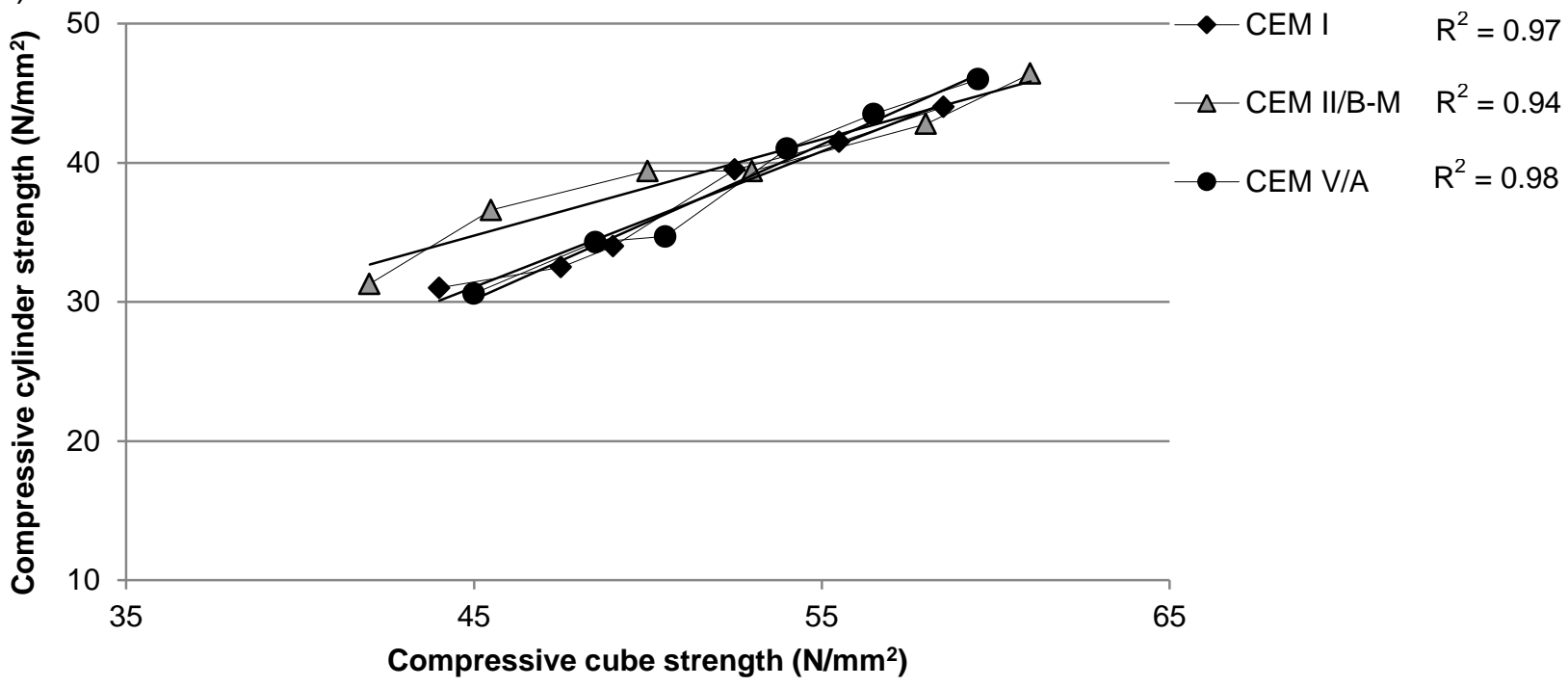

b)

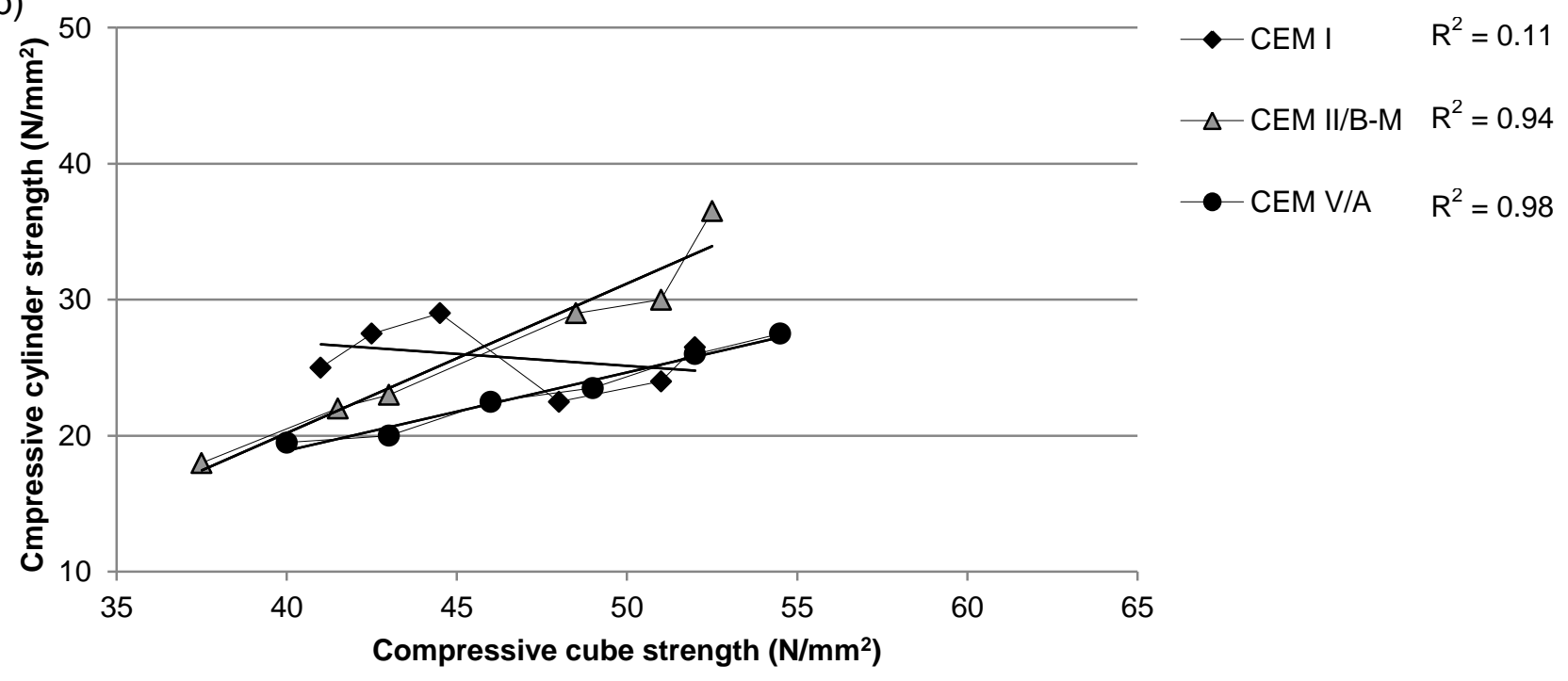

Figure 6. The relationship between compressive cylinder and cube strengths of equal design strength a) NAC and b) RAC mixes at 28, 56 and 91 days 

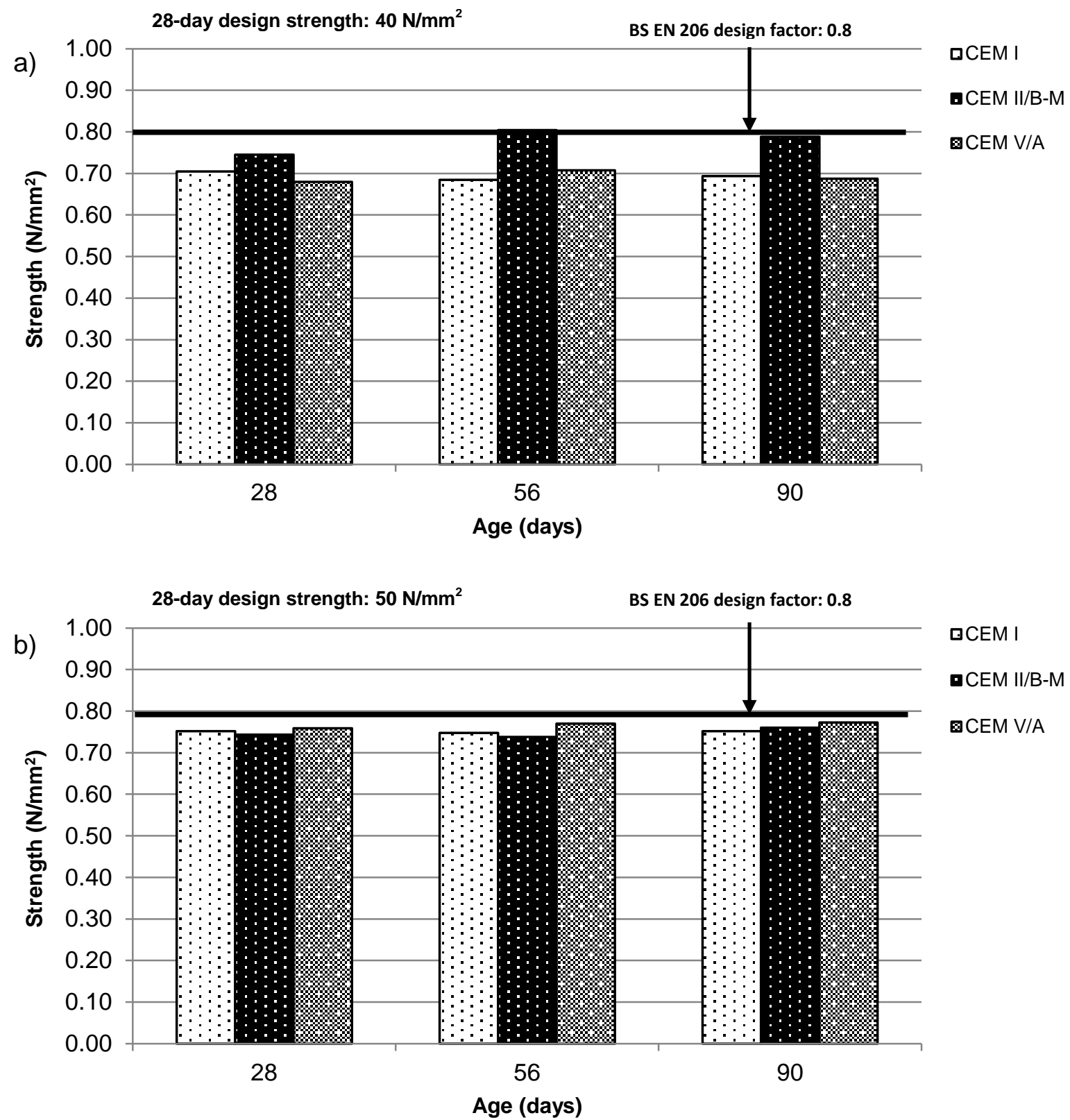

Figure 7. The ratio between compressive cylinder and cubes strengths $\left(f_{\text {cy }} / f_{\text {cube }}\right)$ of NAC mixes 

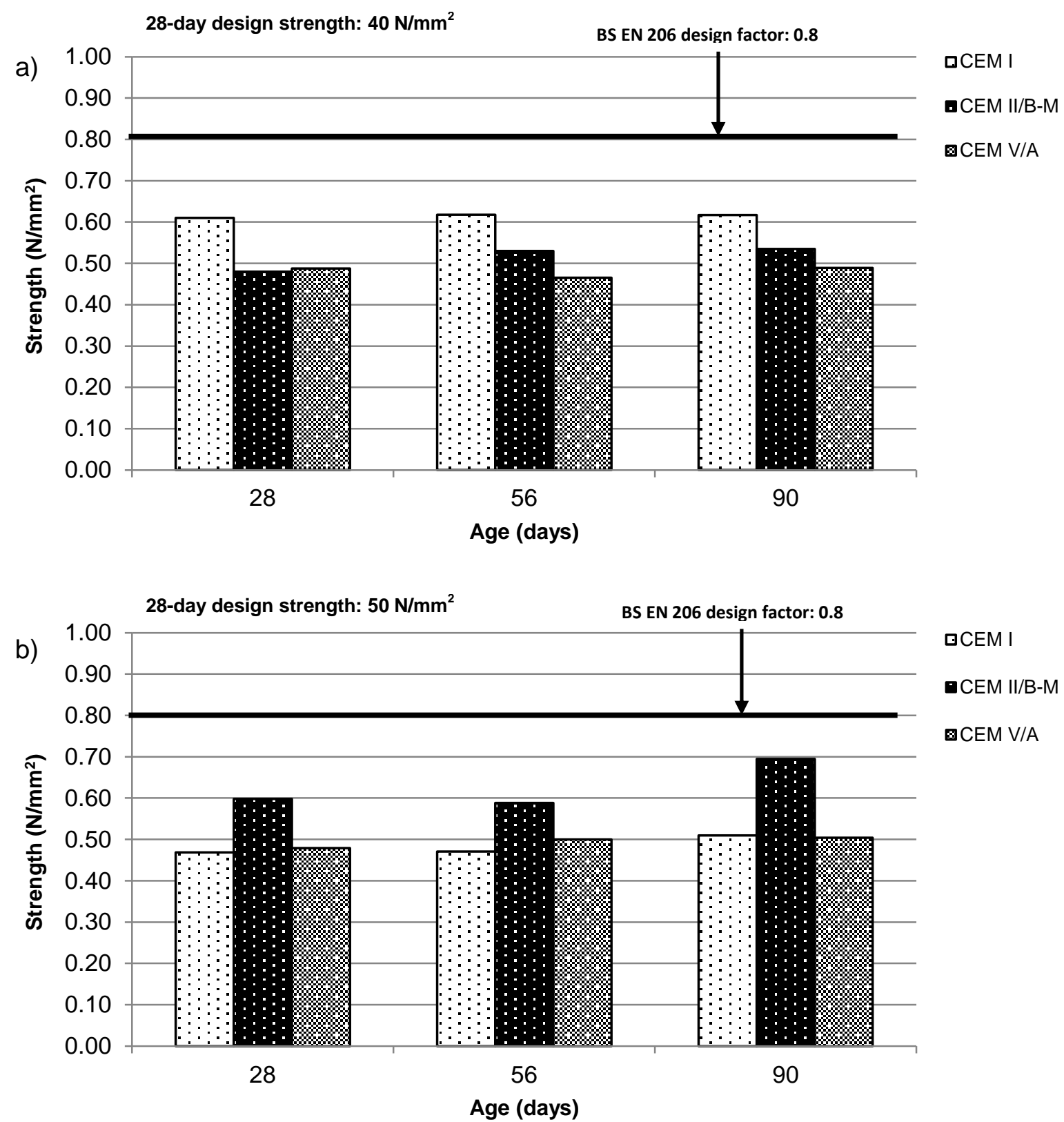

Figure 8. The ratio between compressive cylinder and cubes strengths $\left(f_{\text {cy }} / f_{\text {cube }}\right)$ of RAC mixes 


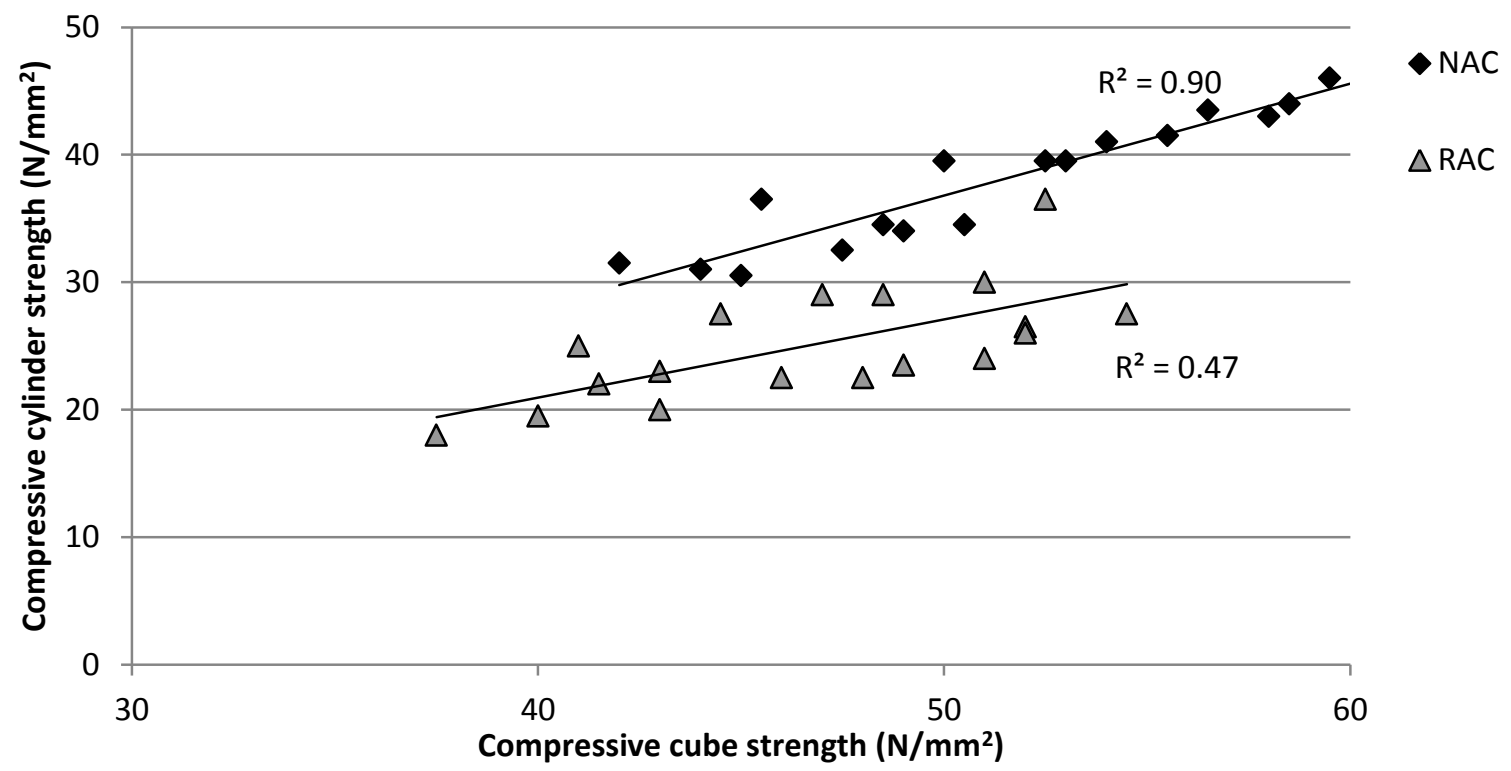

Figure 9. Relationship between compressive cylinder and cube strength for NAC and RAC mixes

\section{Flexural strength}

The results for NAC and RAC mixes are given Figures $10(a)$ and $10(b)$ and $11(a)$ and $11(b)$ respectively for $40 \mathrm{~N} / \mathrm{mm}^{2}$ and $50 \mathrm{~N} / \mathrm{mm}^{2}$ design strength classes. It was observed that CEM I mixes achieved higher strengths than CEM II/B and CEM V mixes at early ages. Similar to compressive cube strength development, it is believed that $\mathrm{PC}$ replacement by the $\mathrm{CMC}$ reduced the available $\mathrm{CaO}$ content available for $\mathrm{CMC}$ to react and produce $\mathrm{CSH}$ gel. Addition to that, lower early strength results of CEM II and CEM V mixes were observed to be compensated at other test ages ( 28 and 56 days) with the contribution of pozzolanic reactions. This is coherent with Akçaözoglu and Atiş [32] that flexural strength of concrete mixes was close to $\mathrm{PC}$ concrete at 28 days.

There is no significant trend observed between NAC and RAC mixes. RAC mixes provided comparable results as NAC mixes for all cement concretes at all ages except $50 \mathrm{~N} / \mathrm{mm}^{2}$ design strength CEM I cement NAC mixes. Previous studies revealed [32, 53] the replacement levels of RA and RGS individually for the optimum performance concrete. However, RAC mixes made with the combination of both RA and RGS was in line with those specified earlier that the use of RA less than $30 \%$ and RGS up to $15 \%$ could provide comparable results as PC mixes. Bond strength between the cement paste and the aggregates is one of the factors in the determination of flexural strength. As use of RA was expected to reduce this bond strength, this performance of RAC mixes is believed to be due to adhesion between the porous and angular shaped RGS particles improved the internal friction, and thus increased the area of contact of interfacial bond between the cement paste and the aggregates. 

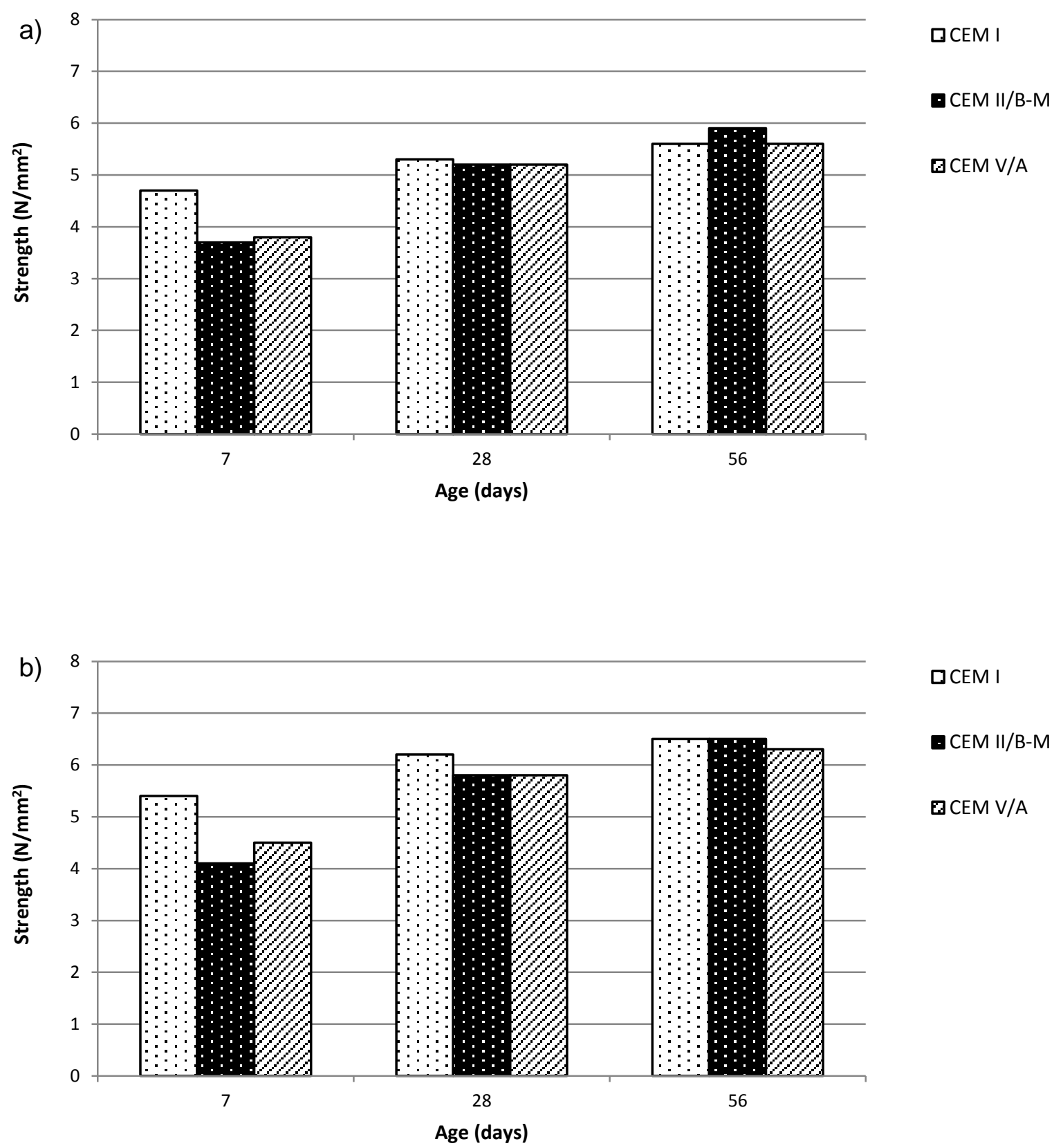

Figure 10. Flexural strengths of a) $40 \mathrm{~N} / \mathrm{mm}^{2}$ and b) $50 \mathrm{~N} / \mathrm{mm}^{2}$ design strength NAC mixes 

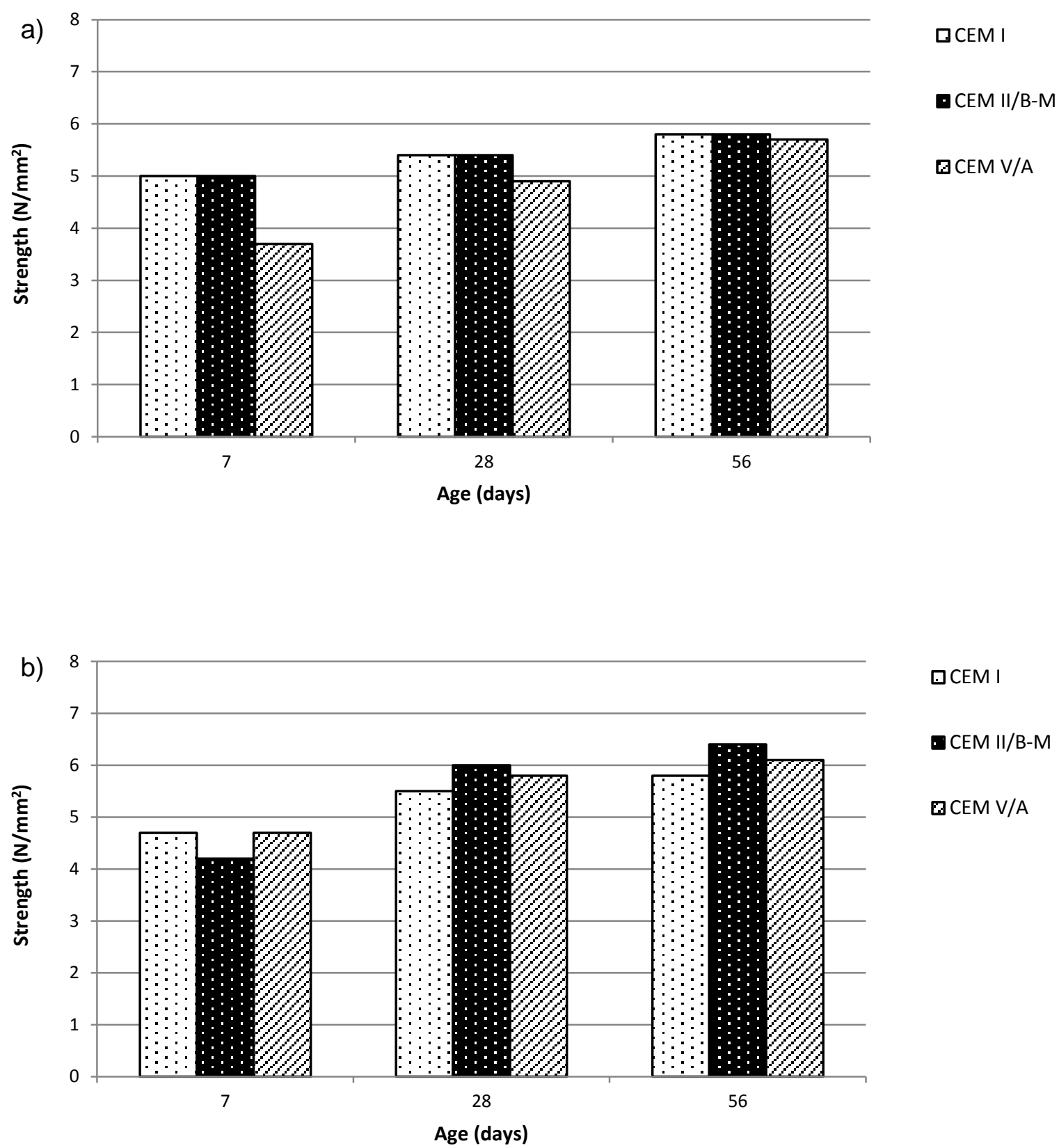

Figure 11. Flexural strengths of a) $40 \mathrm{~N} / \mathrm{mm}^{2}$ and b) $50 \mathrm{~N} / \mathrm{mm}^{2}$ design strength RAC mixes

\subsubsection{Drying shrinkage}

Drying shrinkage is of an important parameter from the structural design point of view for concrete use. Cracks which might arise due to drying shrinkage could have adverse effect on the concrete load bearing capacity.

Figures 12(a) and 12(b) and 13(a) and 13(b) show the drying shrinkage development over time for the mixes investigated. It was observed that CEM I mixes had higher drying shrinkage. This reduction can be explained by CEM II/B and CEM V mixes had lower water contents as it is a well-known fact that water is the major contributor to the drying shrinkage. 
In addition, autogenous shrinkage could be the reason of initially higher drying shrinkage values which is believed to be affected by the porosity of the concrete. However, w/c ratio was not seem to have effect on the shrinkage development of concrete which is in contrast with Qiang [54] that GGBS presence has smaller effect on the drying shrinkage of concrete at lower $\mathrm{w} / \mathrm{c}$ ratios. From the results, it can be seen that CEM II/B and CEM V mixes showed either comparable or higher shrinkage values at first 14 days. This is in line with Qiang [54] that this higher development of GGBS incorporated concretes is due to hydration of GGBS takes places slowly therefore water reacts with the cement paste later than in the PC concrete. It is also believed that permeability influences the phenomenon of water evaporation. Thus as the hydration takes place due to pozzolanic reactions by the CMCs, denser microstructure is formed. This is more pronounced at 14 days and onwards and this hypothesis can be supported with compressive and flexural strength results whereas pozzolanic reaction was observed to contribute to strength between 7 days and 28 days for GGBS inclusive mixes. Unlike existing literature, drying shrinkage values showed reduction earlier, 21 days, than reported previously by Akçaözoğlu [32] and Qiang [54]. In addition, CEM II/B-M cement mixes for both design strength concretes were observed to provide higher shrinkage development at 7 days. Khatri [52] and Güneyisi [60] stated that inclusion of SF increases the fine pores in the matrix and thereby leads to water loss. This also supports previous studies $[15,32,60]$ that the adverse affect of SF was diminished when it is blended with another $\mathrm{CMC}$ in concrete.

In general, there is no specific trend observed between NAC and RAC mixes. However, it was monitored that the use of recycled aggregates prevented early shrinkage development for $50 \mathrm{~N} / \mathrm{mm}_{2}$ design strength concretes which is in contrast with the previous findings [31, 33]. Results for $40 \mathrm{~N} / \mathrm{mm}^{2}$ design strength RAC mixes showed noticeable increase at 21 days and onwards. In contrast to that, $50 \mathrm{~N} / \mathrm{mm}^{2}$ design strength concretes indicated lower drying shrinkage values at all ages except CEM V/A mix at 112 days only. The inconsistency in drying shrinkage results could be due to water added to compensate the higher absorption of recycled aggregates that resulted in increase in drying shrinkage of these concretes. Considering the fact that the same amount of RA was used as a replacement to natural coarse aggregate for both design strengths, the reduction in drying shrinkage could be linked with the use of RGS whereas the use of RGS content was lower in mass for $50 \mathrm{~N} / \mathrm{mm}^{2}$ design strength concretes. This is in agreement with the previous finding by Kou and Poon [21] that the use of RGS reduces drying shrinkage. 

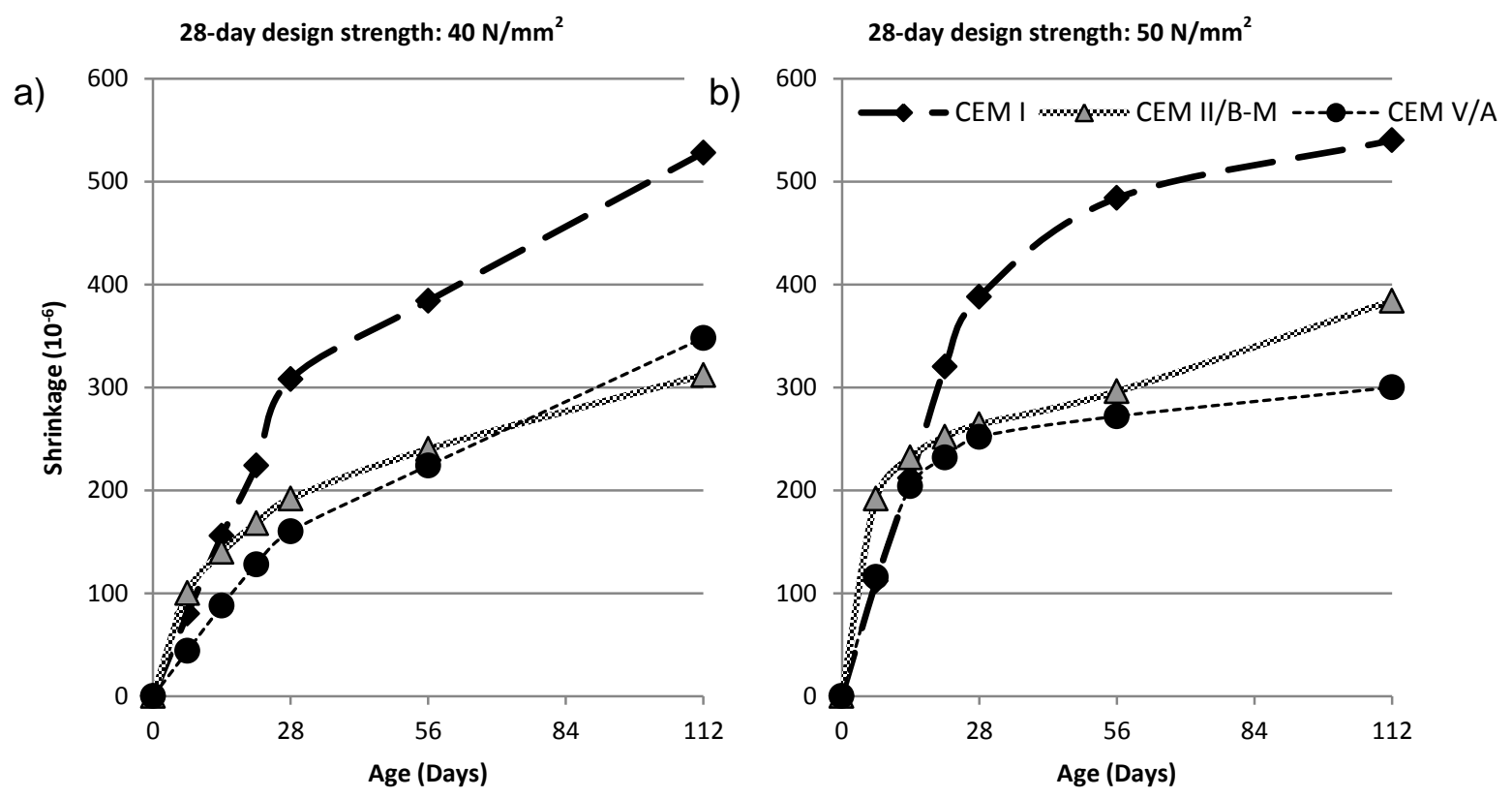

Figure 12. Drying shrinkage values of equal design strength NAC mixes

a)

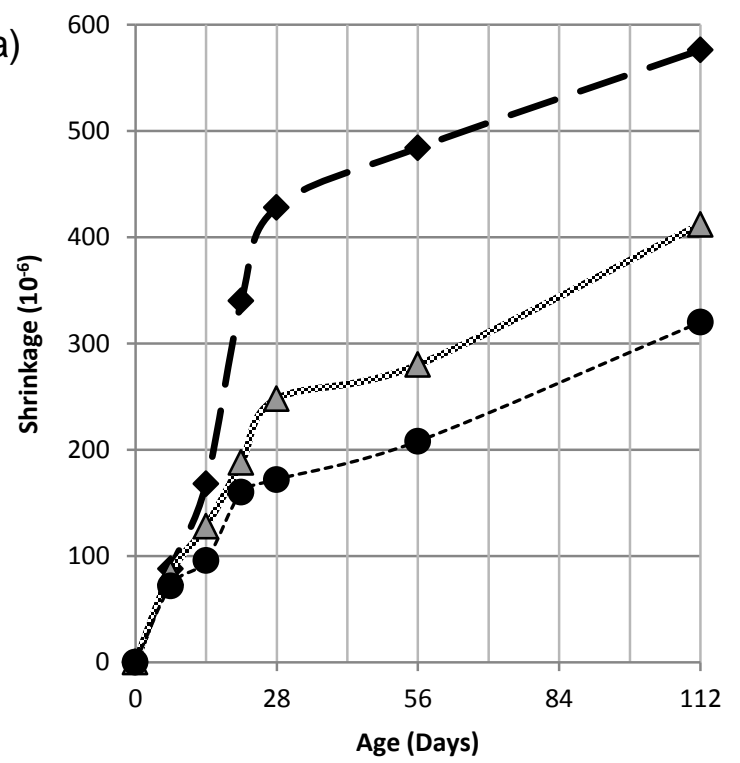

b)

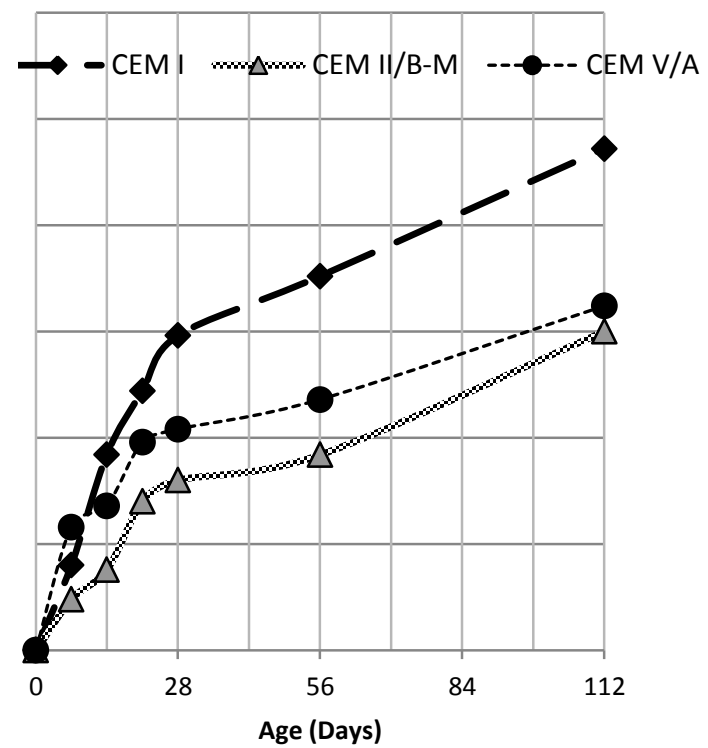

Figure 13. Drying shrinkage values of equal design strength RAC mixes

\subsubsection{Durability properties}

\subsubsection{Initial surface absorption test}

The ISAT-10 results and N-values for developed concrete are given in Table 7. In addition, Figures 14 and 15 show the relationship between ISAT-10 values and 28-days compressive cube strength for NAC and RAC mixes respectively. ISAT-10 results indicated that CEM II and CEM V cement concretes can reduce porosity of concrete dramatically in comparison to 
CEM I cement concretes for the same design strength. This may be attributed to refinement of pore structure of the concrete provided by the pozzolanic reactions of the additional cementitious constituents. It is noteworthy to mention that for the same cement type ISAT-10 values increased as the compressive cube strength increased except CEM II/B-M cement concretes. Although CEM II/B cement concretes have comparable or higher w/c ratios compared to CEM I cement concretes, the ISAT-10 values showed significant reduction. This is believed to be due to finer characteristics of additional cementitious constituents improved the pore structure of concretes. In addition to these, CEM II/B-M composite cement concretes with the lowest total cementitious contents amongst developed concretes also indicated significantly reduced ISAT-10 values. This could be due to the presence of SF with its extreme fineness improved the pore structure. This phenomenon can also be supported by the reduction in the ISAT-10 values of CEM II/B-M cement concrete as the SF content increased with the increasing design strength. Apart from this, CEM V cement concretes also demonstrated remarkable reduction in ISAT-10 values. This is attributed to lower $w / c$ ratios and higher binder contents of these concretes in comparison to CEM I cement concretes formed dense matrix and reduced permeability.

It can be seen from Table 7 that the contribution of recycled aggregates with a particular replacement levels to BS EN 197-1 cement concretes showed slightly higher ISAT-10 values compared to BS EN 197-1 cement concretes made with natural aggregates. This increase is believed to be due to recycled aggregate incorporation lead to an increase in the porous matrix. For both type of aggregate concretes, similar trends were reported. As it is seen in figures 14 and 15, there was no relation between the w/c ratio and ISAT-10 for BS EN 197-1 cement concretes except CEM II/B-M cement concretes which ISAT-10 values were observed to decrease with the increasing compressive cube strength.

Table 7. ISAT-10 and $\mathrm{N}$ value results of equal design strength NAC mixes

\begin{tabular}{ccccc}
\hline $\begin{array}{c}\text { 28-day design } \\
\text { strength }\end{array}$ & Cement & w/c ratio & $\begin{array}{c}\text { ISAT-10 } \\
\left(\mathbf{m l}^{\mathbf{2}} \mathbf{m} / \mathbf{s}\right) \mathbf{x} \mathbf{1 0}^{-2}\end{array}$ & $\begin{array}{c}\mathbf{N}-\mathbf{v a l u e} \\
\left(\mathbf{1 0}^{-2}\right)\end{array}$ \\
\hline \multirow{3}{*}{$40 \mathrm{~N} / \mathrm{mm}^{2}$} & CEM I & 0.51 & 42.8 & 57.9 \\
& CEM II/B-M & 0.55 & 24.0 & 31.9 \\
& CEM V/A & 0.40 & 19.7 & 26.1 \\
\hline \multirow{3}{*}{$50 \mathrm{~N} / \mathrm{mm}^{2}$} & CEM I & 0.41 & 44.4 & 60.2 \\
& CEM II/B-M & 0.41 & 19.2 & 22.2 \\
& CEM V/A & 0.38 & 23.5 & 29.4 \\
\hline
\end{tabular}

Table 8. ISAT-10 and $\mathrm{N}$ value results of equal design strength RAC mixes

\begin{tabular}{ccccc}
\hline $\begin{array}{c}\text { 28-day design } \\
\text { strength }\end{array}$ & Cement & w/c ratio & $\begin{array}{c}\text { ISAT-10 } \\
\left(\mathbf{m l} / \mathbf{m}^{2} / \mathbf{s}\right) \mathbf{1} \mathbf{1 0}^{-\mathbf{2}}\end{array}$ & $\begin{array}{c}\mathbf{N} \text {-value } \\
\left(\mathbf{1 0 ^ { - 2 }}\right)\end{array}$ \\
\hline \multirow{3}{*}{$40 \mathrm{~N} / \mathrm{mm}^{2}$} & CEM I & 0.51 & 45.4 & 60.9 \\
& CEM II/B-M & 0.55 & 28.2 & 36.7 \\
& CEM V/A & 0.40 & 24.5 & 36.2 \\
\hline \multirow{3}{*}{$50 \mathrm{~N} / \mathrm{mm}^{2}$} & CEM I & 0.41 & 47.7 & 63.9 \\
& CEM II/B-M & 0.41 & 20.6 & 25.4 \\
& CEM V/A & 0.38 & 29.2 & 40.2 \\
\hline
\end{tabular}



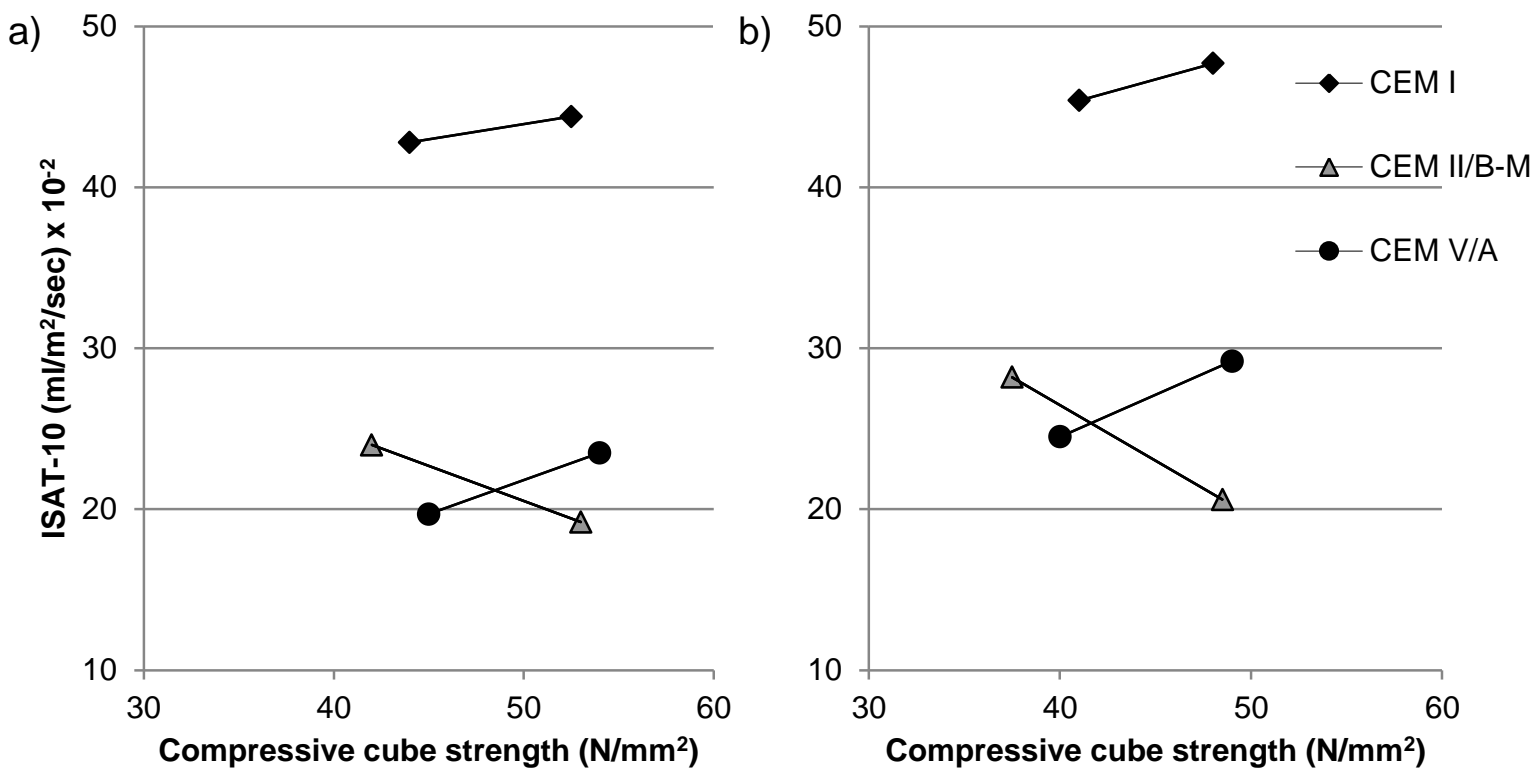

Figure 14. The relationship between ISAT-10 values and 28-day compressive cube strength for a) NAC and b) RAC mixes

\subsubsection{Carbonation resistance}

It can be seen from the results that the depth of carbonation is proportional to the duration of exposure, thus carbonation depth increased as the exposure period increased. However, there was no relation between carbonation depth and compressive strength of concrete. Thus, CEM I cement concretes achieved better resistance to carbonation compared to CEM II/B and CEM V cement concretes. Moreover, it was observed that lower the w/c ratio, the better carbonation resistance observed for different design strength concretes made with the same cement.

On the other hand, the content of calcium hydroxide $(\mathrm{CH})$ and carbon dioxide penetration rate are the two key factors controlling concrete carbonation rate. Therefore, the reduction in resistance to carbonation of CEM II/B and CEM V cement concretes could be attributed to replacing $\mathrm{PC}$ with additional cementitious constituents reduced $\mathrm{CH}$ content available in the pore structure due to its consumption by the pozzolanic reaction in cementitious system. This can also be clearly seen from the results that difference between the control and CEM II cement mixes was less comparing to CEM V cement concretes as FA had lower $\mathrm{CaO}$ content comparing to GGBS. Moreover, GGBS is more active additional cementitious constituent compared to FA, therefore early activation of pozzolanic reaction leads to lower $\mathrm{CH}$ content and provide denser matrix concretes.

Similar trend as BS EN 197-1 cement concrete was observed for RAC mixes whereas CEM II/B and CEM V cement concretes indicated higher carbonation depths than CEM I cement concretes as expected. However, CEM V/A cement $50 \mathrm{~N} / \mathrm{mm}^{2}$ design strength concrete showed comparable carbonation values which could also be attributed to pore refinement of concrete matrix due to higher binder content. For both aggregate type concretes, carbonation depth increased as the period of exposure increased. It can also be seen that 
RAC mixes performed higher carbonation depths in comparison to NAC mixes. However, it is thought that the use presence of additional cementitious constituents could have the same affect on both concretes due to both concretes had the same total cementitious contents and compositions. Also, it is important to point out that in some cases recycled aggregates coming from construction demolition resides may already carbonated, as this may influence such performance. As RGS and NF aggregates had quite similar water absorption, this increase in carbonation depth could be due to higher water absorption of RA compared to NC. Considering carbonation of concrete takes place at a relative humidity of about $40 \%$ to $70 \%$, the higher water absorption of RA is believed to result in lower moisture content for recycled aggregates concretes. Thus, it caused more porous concrete matrix which $\mathrm{CO}_{2}$ penetrated further compared to NAC mixes. Moreover, there is a strong relation observed between the carbonation depth and loss of workability.
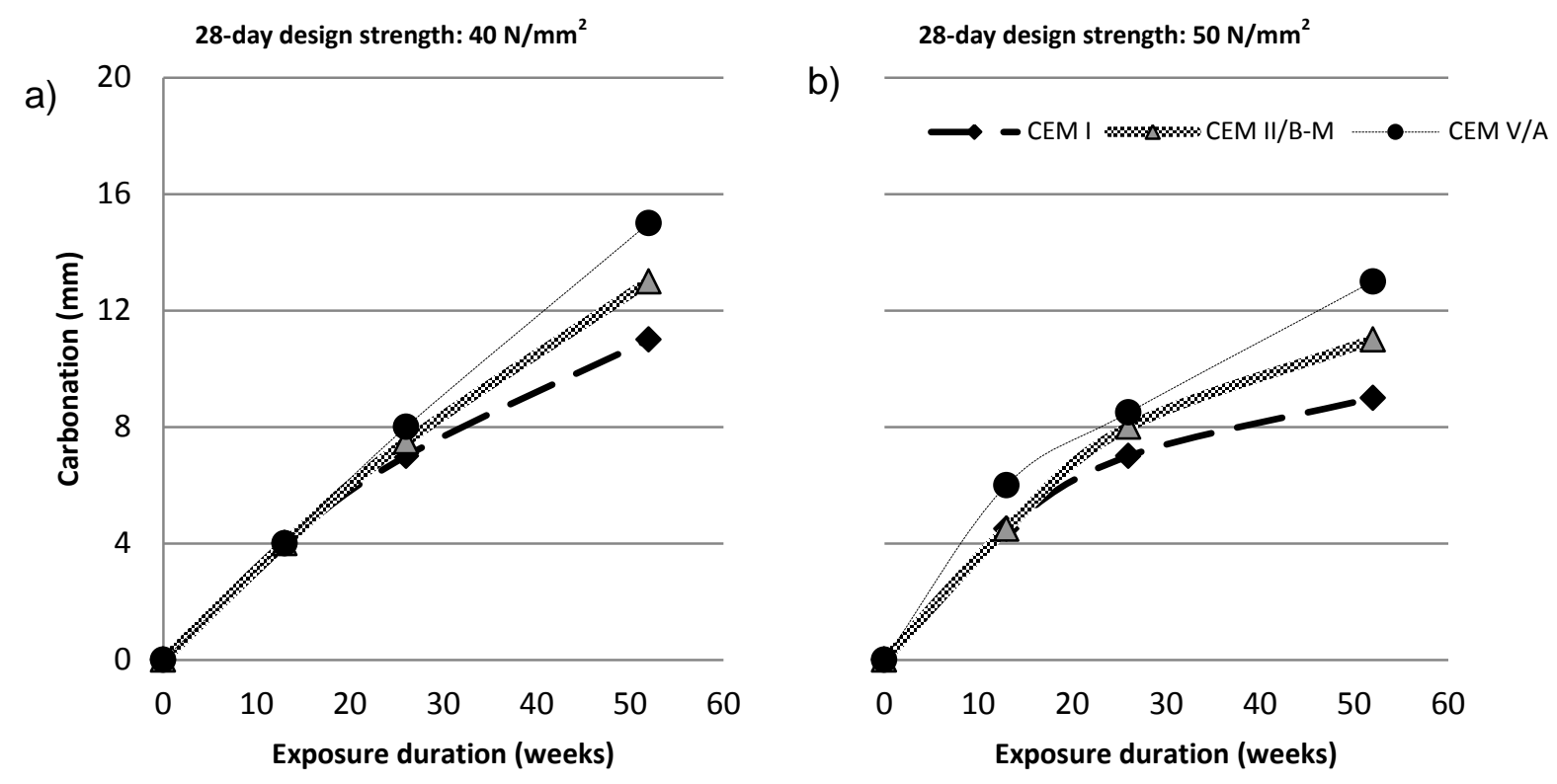

Figure 15. Carbonation penetration of equal design strength NAC mixes design strength NAC mixes 
28-day design strength: $40 \mathrm{~N} / \mathrm{mm}^{2}$

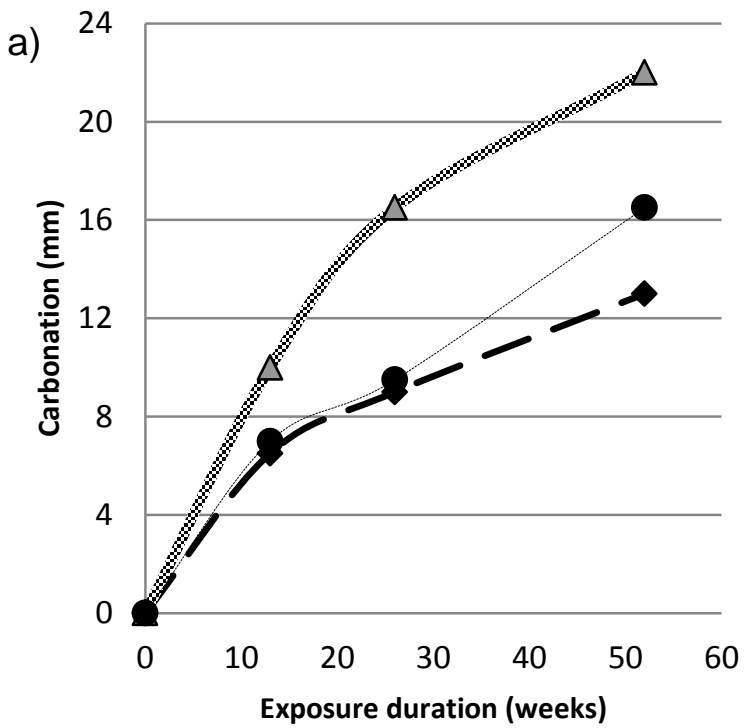

28-day design strength: $50 \mathrm{~N} / \mathrm{mm}^{2}$

b)
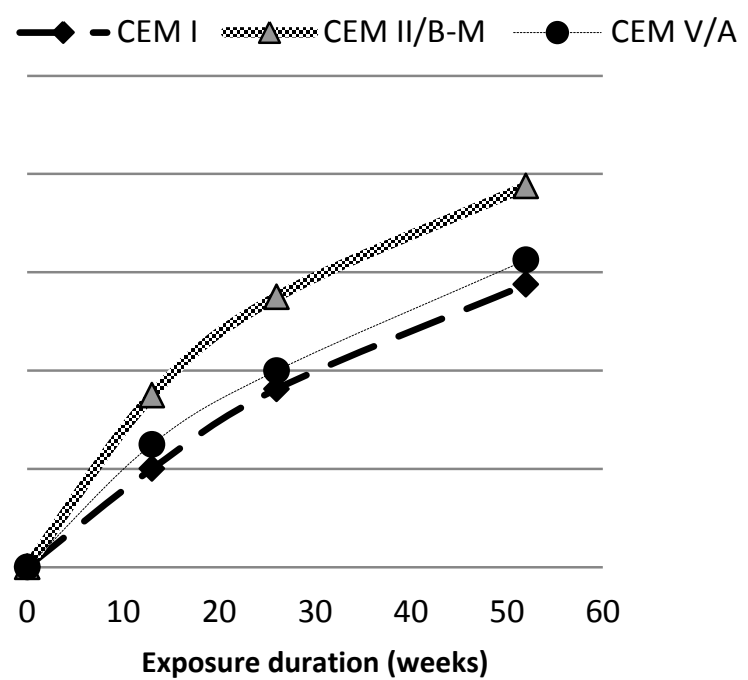

Figure 16. Carbonation penetration of equal design strength RAC mixes design strength NAC mixes

Table 9. The relationship between 365 days compressive cube strength and carbonation depths at the end of exposure period for NAC mixes

\begin{tabular}{cccc}
\hline Cement & Design strength & $\begin{array}{c}\text { Compressive cube } \\
\text { strength }\left(\mathbf{N} / \mathbf{m m}^{2}\right)\end{array}$ & $\begin{array}{c}\text { Carbonation depth } \\
\text { (mm) }\end{array}$ \\
\hline CEM I & $40 \mathrm{~N} / \mathbf{m m}^{2}$ & 53 & 11 \\
& $50 \mathrm{~N} / \mathrm{mm}^{2}$ & 64 & 9 \\
\hline CEM II/B-M & $40 \mathrm{~N} / \mathrm{mm}^{2}$ & 54.5 & 13 \\
& $50 \mathrm{~N} / \mathrm{mm}^{2}$ & 67 & 10.75 \\
\hline CEM V/A & $40 \mathrm{~N} / \mathrm{mm}^{2}$ & 56.5 & 15 \\
& $50 \mathrm{~N} / \mathrm{mm}^{2}$ & 66 & 13 \\
\hline
\end{tabular}

Table 10. The relationship between 365 days compressive cube strength and carbonation depths at the end of exposure period for RAC mixes

\begin{tabular}{cccc}
\hline Cement & Design strength & $\begin{array}{c}\text { Compressive cube } \\
\text { strength }\left(\mathbf{N} / \mathbf{m m}^{\mathbf{2}}\right)\end{array}$ & $\begin{array}{c}\text { Carbonation depth } \\
\text { ( } \mathbf{m m})\end{array}$ \\
\hline CEM I & $40 \mathrm{~N} / \mathbf{m m}^{2}$ & 48 & 13 \\
& $50 \mathrm{~N} / \mathbf{m m}^{2}$ & 56 & 11.5 \\
\hline CEM II/B-M & $40 \mathrm{~N} / \mathrm{mm}^{2}$ & 49.5 & 22 \\
& $50 \mathrm{~N} / \mathrm{mm}^{2}$ & 58 & 15.5 \\
\hline CEM V/A & $40 \mathrm{~N} / \mathrm{mm}^{2}$ & 53.5 & 16.5 \\
& $50 \mathrm{~N} / \mathrm{mm}^{2}$ & 62.5 & 12.5 \\
\hline
\end{tabular}




\section{Practical implications}

In the aim of using more environmentally friendly cement types through reducing PC level and use of other permitted cementitious constituents level is not is not a practical approach as the use of CMC at higher replacement levels can affect the workability of concrete if not appropriate amount of SP used. Due to reduced free water content of CEM II/B and CEM V mixes based on the binder used in accordance with the guidance of BRE mix design document, it is necessary to use SP to improve the fresh properties of concrete. The study has also shown that use of recycled aggregates in environmentally friendly concrete production could affect the workability of the concrete unless the convenient amount of SP is used due to higher WA of recycled aggregates. It was observed that CEM II/B-M (65PC/30GGBS/5SF) cement could be a practical approach to use in production of sustainable concrete from the fresh properties point of view. It is important to point out that other alternative technologies are also available for increasing recycled aggregates for more sustainable construction [61-63].

It was observed that compressive cylinder strength results indicated that the use of 40 $\mathrm{N} / \mathrm{mm}^{2}$ design strength CEM II/B-M (65PC/30GGBS/5SF) cement concretes may be used in structural members under compression. In contrast to that, the use of recycled aggregates in CEM II/B-M and CEM V/A cement concrete is not practically applicable to use for cylindrical concrete members such as spiral columns. Similar to compressive strength performances, CEM II/B and CEM V cement RAC mixes could be practically be used in concrete beam members if early strength is not of a concern and supported with appropriate scaffolding until the pozzolanic reaction takes place to compensate early strength loss. On the other hand, the use of CEM II/B and CEM V cements in NAC and CEM II/B-M and CEM V/A cement in $\mathrm{RAC}$ production is not a practical approach as far as fast track construction is concerned. This may require the longer period for formwork to be removed due to lower early strength development of designed concrete mixes or otherwise, developed concretes may be used for non-load bearing applications where early strength is not of a concern. Considering CEM II/B and CEM V cement NAC mixes had higher strength developments, these concretes can be practically applicable if cured adequately until pozzolanic reactions take place. However, the use of recycled aggregates in CEM II/B-M and CEM V/A mixes may potentially be used if loss of strength margin is kept within $\pm 10 \%$. Moreover, the use of CEM II/B and CEM V cement in concrete production has a potential to use in structural concrete construction with reduced drying shrinkage which could prevent cracking formation in comparison to CEM I cement concretes.

The near surface concrete is affected by the compaction of fresh concrete and results in the movement of the cement paste and aggregates while concrete surface happens to be heterogeneous. For this reason, near surface concrete have different permeation characteristics than the internal part of the concrete. Therefore, the ISA is one of the important parameters in the determination of durability of concrete. It was observed that the use of CEM II/B and CEM V cement in concrete production has a strong potential to use to produce more durable concretes. In addition, the use of recycled aggregates in CEM II/B-M and CEM V/A mixes may also be a practical approach from the durability point of view. Consequently, the use of CEM II/B-M and CEM V/A cements in RAC mixes as defined in this research have a potential to be used in concrete where concrete surface is exposed to hazardous chemicals that might lead to deterioration of concrete structure such as 
carbonation, chloride ingress and sulphate attack. The carbonation of concrete was influenced by the use of CEM II/B and CEM V cements and recycled aggregates. However, resistance to carbonation was observed to be related with the loss of workability over time. Briefly, the use of CEM II/B and CEM V cements in NAC and RAC mixes could potentially lead to corrosion of reinforcing bars in structural concrete members due to reduced alkalinity. The corrosion may then reduce the load bearing capacity of concrete. The effect of both CEM II/B and CEM V cements and recycled aggregates on concrete carbonation is not to be disregarded. Therefore, the loss of workability over time should be reduced by increasing SP content to reduce concrete porosity in order to be practically applicable. In parallel with this, appropriate handling and adequate curing of concrete also to be paid attention if used in the structural concrete members. The use of CEM II/B and CEM V cements in NAC and RAC mixes may be a practical approach if higher cover to reinforcement is used. In addition, CEM II/B and CEM V cements if used with recycled aggregates, may require a slightly higher cover to reinforcement compared to CEM II/B and CEM V cement NAC mixes.

\section{Conclusions}

Technical information regarding to the fresh and hardened (engineering and durability) performances of concretes made with Portland-slag and composites cements and recycled aggregates was observed in this study. The main conclusions identified are stated below:

- The study has shown that use of cement main constituents increased SP demand required to achieve the same design consistency class. The increment in SP demand has become dramatic as the replacement level of CMC increased. In addition, SP demand increased as the design strength increased. RAC mixes required higher SP dosage for the desired workability class due to higher WA capacities of recycled aggregates.

- $\quad$ RAC mixes required higher SP dosage for the desired workability class due to higher WA capacities of recycled aggregates.

- The results have shown that CF values decreased with the increased design strength due to increased fine contents by increasing total cementitious contents and thereby lowering w/c ratios. CEM II/B and CEM $V$ mixes have lead to higher loss of workability over time, particularly with the increased CMC, in comparison to CEM I mixes. However, the effect of $w / c$ ratio on the loss of workability over time was more evident for CEM V mixes compared to CEM II/B mixes. RAC mixes had lower CF values except concretes made with CEM II/B-M cements. This may due to smooth characteristics of GGBS particles and use of SP dispersed cement and SF particles that increased fluidity and diminished the cohesiveness of the concrete mix.

- Developed CEM II/B and CEM V mixes reached the design strength at 28 days showing the suitability of environmentally friendly concrete production by reducing 
$\mathrm{PC}$ content with $\mathrm{CMC}$ and recycled aggregates and adjusting the $\mathrm{w} / \mathrm{c}$ ratio depending CMC used.

- The use of CEM II/B and CEM V cements in concrete production reduced the strength at early ages (<7days) compared to PC concretes. The contribution of pozzolanic reactions to strength was observed to take place between 7 and 28 days. CEM II/B and CEM V mixes achieved higher compressive cube strengths compared to conventional mixes at post 28-days. The use of recycled aggregates with particular replacement ratios reduced the strength compared to CEM II/B-M and CEM V/A cement NAC mixes. However, this can be negligible as long as strengths are within the defined margin of $10 \%$ strength loss. In addition, compressive cylinder strength results for RAC mixes indicated remarkable reduction. In contrast to that, CEM II/B-M and CEM V/A cement RAC mixes were observed to improve concrete flexural strength compared to corresponding CEM II/B-M and CEM V/A cement NAC mixes.

- $\quad$ CEM II/B and CEM V mixes resulted in higher shrinkage development at 7 days. In addition, CEM II/B and CEM V/A cement concrete mixes reduced drying shrinkage after 14 days and onwards (until 112 days) which this suggests that pozzolanic reaction takes place after 14 days. While there was no apparent effect of using recycled aggregate on the concrete drying shrinkage. Drying shrinkage values of RAC mixes were higher for $40 \mathrm{~N} / \mathrm{mm}^{2}$ design strength concretes and lower for 50 $\mathrm{N} / \mathrm{mm}^{2}$ than corresponding NAC mix.

- The near surface absorption was affected by the type and amount of cementitious constituents and aggregate types used. The ISAT-10 results showed that the use of CEM II/B and CEM V cements reduced the concrete permeability considerably. Rate of decay, N-value, showed similar trend as ISAT-10 values. The use of recycled aggregates, RA and RGS, in RAC mixes increased concrete permeability slightly compared to NAC mixes.

- The resistance to carbonation was influenced by the $w / c$ ratios and the amount of CMC used. The use of CEM II/B and CEM V cements increased carbonation penetration of concrete except CEM II/B-V mixes. A relationship between w/c ratio and carbonation resistance was found for concretes made with the same type of cements. Thus, the lower w/c ratio, the better carbonation resistance was reported for different design strength concretes. The use of RGS is believed have no effect on carbonation resistance, while the use of RA increased the carbonation depth noticeably. 


\section{Acknowledgement}

The authors would like to acknowledge Hanson UK, Elkem AS, Grace Construction Products Ltd. and Day Group Ltd. for providing the materials for the presented work.

\section{References}

1. UK Greenhouse Gas Statistics \& Inventory Team, Science and Innovation Group, Department of Energy and Climate Change (2012) UK GREENHOUSE GAS EMISSIONS: PERFORMANCE AGAINST EMISSIONS REDUCTION TARGETS 2012 PROVISIONAL FIGURES.

2. British Standard Institution. BS EN 197-1 Cement. (2011) Composition, specifications and conformity criteria for common cements. BSI. London.

3. Greenspec (2016) Greenspec - Green Building Design, Products and Materials in the UK [online]. UK: Wakefield [cited 2nd July 2016]. <http://www.greenspec.co.uk/building-design/environmental-impacts-of-concrete/>

4. Concrete construction (2012) Concrete Construction: Resources for contractors and specifiers including construction methods, materials and equipment. [online]. Washington: Hanley Wood Media. $<$ http://www.concreteconstruction.net/aggregates/global-demand-for-constructionaggregates-to-exceed-48-billion-metric-tons-in-2015.aspx>

5. British Standard Institution. BS EN 12620 Aggregates for concrete (2013) BSI. London.

6. British Standard Institution. BS 8500-1:2006+A1:2012 Concrete - Complementary British Standards to BS EN 206-1. (2006) Method of specifying and guidance for the specifier. BSI. London.

7. British Standard Institution. BS 8500-2:2006+A1:2012 Concrete - Complementary British Standards to BS EN 206-1. (2006) Specification for constituent materials and concrete. BSI. London.

8. Mineral Products Association (2013) Concrete Industry Sustainability Performance Report. UK: The Concrete Centre.

9. Sustainable Concrete Forum (no date) Home Page. [online]. UK: MPA The Concrete Centre. [cited 3rd July 2016]. 
$<\mathrm{http}: / /$ www.sustainableconcrete.org.uk/top_nav/uk_construction_industry/aggregate _levy.aspx>

10. Mineral Products Association (no date) Mineral Products Association (MPA) - the trade association for the aggregates, asphalt, cement, concrete, lime, mortar and silica sand industries. [online]. London: Mineral Products Association. [cited 4th July 2014]. <http://www.mineralproducts.org/prod_agg_recy01.htm>

11. University of Dundee (2005) www.greenconcrete.dundee.ac.uk. [online] Scotland: University of Dundee. [cited 4th July 2016]. <http://www.greenconcrete.dundee.ac.uk/RecycledGlass.htm>

12. Jianyong, L. and Yan, Y. (2001) A study on creep and drying shrinkage of high performance concrete. Cement and Concrete Research. 31, pp.1203-06.

13. Sabet, F.A., Libre, N.A. and Shekarchi, M. (2013) Mechanical and durability properties of self consolidating high performance concrete incorporating natural zeolite, silica fume and fly ash. Construction and Building Materials. 44, pp.175-184.

14. Limbachiya, M., Meddah, M.S. and Ouchagour, Y. (2012) Use of recycled concrete aggregate in fly-ash concrete. Construction and Building Materials. 27, pp.439-449.

15. Gesoğlu M., Güneyisi, E. and Özbay, E. (2009) Properties of self-compacting concretes made with binary, ternary, and quaternary cementitious blends of fly ash, blast furnace slag, and silica fume. Construction and Building Materials. 23 (5), pp.1847-54.

16. Erdem, T.K. and Kirca, O. (2008) Use of binary and ternary blends in high strength concrete. Construction and Building Materials. 22, pp.1487-1493.

17. Tu, T.Y., Chen, Y.Y. and Hwang, C.L. (2006) Properties of HPC with recycled aggregates. Cement and Concrete Research. 36, pp.943-50.

18. Limbachiya, M.C. (2009) Bulk engineering and durability properties of washed glass sand concrete. Construction and Building Materials. 23, pp.1078-83.

19. Taha, B. and Nounu, G. (2009) Utilizing Waste Recycled Glass as Sand/Cement Replacement in Concrete. Journal of Materials in Civil Engineering. 21, pp.709-21.

20. Megat Johari, M.A., Brooks, J.J., Kabir, S. and Rivard, P. (2011) Influence of supplementary cementitious on engineering properties of high strength concrete. Construction and Building Materials 25 (5), pp.2639-2648.

21. Kou, S.C. and Poon, C.S. (2009) Properties of self-compacting concrete prepared with recycled glass aggregate. Cement \& Concrete Composites. 31, pp.107-13. 
22. Kuder, K., Lehman, D., Berman, J., Hannesson, G. and Shogren, R. (2012) Mechanical properties of self consolidating concrete blended with high volumes of fly ash and slag. Construction and Building Materials 34, pp.285-95.

23. Bernal, S.A., de Gutiérrez, R.M., Pedraza, A.L., Provis, J.L., Rodriguez, E.D. and Delvasto, S. (2011) Effect of binder content on the performance of alkali-activated slag concretes. Cement and Concrete Research. 41, pp.1-8.

24. Gönen, T. and Yazıcıoğlu, S. (2007) The influence of mineral admixtures on the short and long-term performance of concrete. Building and Environment. 42 (8), pp.308085.

25. Park, C.K. and Noh, M.H. (2005) Rheological properties of cementitious materials containing mineral admixtures. Cement and Concrete Research. 35, pp.842-9.

26. Sim, J. and Park, C. (2011) Compressive strength and resistance to chloride ion penetration and carbonation of recycled aggregate concrete with varying amount of fly ash and fine recycled aggregate. Waste Management. 31 (11), pp.2352-2360.

27. Song, H. and Saraswathy, V. (2006) Studies on the corrosion resistance of reinforced steel in concrete with ground granulated blast-furnace slag - an overview. Journal of Hazardous Materials B138, pp.226-33.

28. Abbas, A., Gholamreza, F., Isgor, O.B. and Razaqpur, A.G. (2009) Durability of recycled aggregate concrete designed with equivalent mortar volume method. Cement \& Concrete Composites. 31, pp.555-63.

29. Limbachiya, M., Meddah, M.S., Fotiadou, S. (2012) Performance of granulated foam glass concrete. Construction and Building Materials. 28, pp.759-68.

30. Guneyisi, E., Gesoglu, M. and Ozbay, E. (2010) Strength and drying shrinkage properties of self-compacting concretes incorporating multi-system blended mineral admixtures. Construction and Building Materials. 24, pp.1878-1887.

31. Kou, S.C. and Poon, C.S. (2012) Enhancing the durability properties of concrete prepared with coarse recycled aggregate. Construction and Building Materials. 35, pp.69-76.

32. Akçaözoglu, S. and Atis, C.D. (2011) Effect of Granulated Blast Furnace Slag and fly ash addition on the strength properties of lightweight mortars containing waste PET aggregates. Construction and Building Materials. 25 (10), pp.4052-4058.

33. Hui-sheng, S., Bi-wan, X. and Xiao-chen, Z. (2009) Influence of mineral admixtures on compressive strength, gas permeability and carbonation of high performance concrete. Construction and Building Materials. 29, pp.1985-1990. 
34. Jones, M.R., Dhir, R.K. and Magee, B.J. (1997) Concrete Containing Ternary Blended Binders: Resistance to Chloride Ingress and Carbonation. Cement and Concrete Research. 27 (6), pp.825-31.

35. Soares, D., de Brito, J., Ferreira, J. and Pacheo, J. (2014) Use of recycled aggregates from precast concrete rejects: Mechanical and durability performance. Construction and Building Materials. 71, pp.263-72.

36. de Castro, S. and de Brito, J. (2013) Evaluation of the durability of concrete made with crushed glass aggregates. Journal of Cleaner Production. 41, pp.7-14.

37. Sabet, F.A., Libre, N.A. and Shekarchi, M. (2013) Mechanical and durability properties of self consolidating high performance concrete incorporating natural zeolite, silica fume and fly ash. Construction and Building Materials. 44, pp.175-184.

38. Thomas, C., Setién, J., Alaejos, P. and de Juan, M.S. (2013) Durability of recycled aggregate concrete. Construction and Building Materials. 40, pp.1054-65.

39. British Standard Institution. BS EN 15167-1 Ground granulated blast furnace slag for use in concrete, mortar and grout. (2006) Definitions, specifications and conformity criteria. BSI. London.

40. British Standard Institution. BS EN 450-1 Fly ash for concrete. (2012) Definition, specifications and conformity criteria. BSI. London.

41. British Standard Institution. BS EN 13263-1 Silica fume for concrete. (2009) Conformity evaluation. BSI. London.

42. British Standard Institution. BS EN 934-2:2009+A1:2012 Admixtures for concrete mortar and grout (2009) Concrete admixtures. Definitions, requirements, conformity, marking and labelling. BSI. London.

43. Building Research Establishment Ltd. (1997) Design of normal concrete mixes. 2nd ed., London: Construction Research Communications Ltd.

44. British Standard Institution. BS EN 206-1 Concrete. (2013) Specification, performance, production and conformity. BSI. London.

45. British Standard Institution. BS EN 12390-3 Testing hardened concrete (2009) Compressive strength test of test specimens. BSI. London.

46. British Standards Institution. BS ISO 1920-8 Testing hardened concrete (2009) Determination of the drying shrinkage of concrete for samples prepared in the field or in the laboratory.

47. British Standard Institution. BS 1881-208 Testing concrete (1996). Recommendations for the determination of the initial surface absorption of concrete. BSI. London. 
48. Nikbin, I.M., Dehestani, M., Beygi, M.H.A. and Rezvani, M. (2014) Effects of cube size and placement direction on compressive strength of self-consolidating concrete. Construction and Building Materials. 59, pp.144-150.

49. British Standard Institution. BS 1881-210 Testing hardened concrete (2013) Determination of the potential carbonation resistance of concrete - Accelerated carbonation method. BSI. London.

50. Borges, P.H.R., Costa, J., Milestone, N.B., Lynsdale, C.J. and Streatfield, R.E. (2010) Carbonation of $\mathrm{CH}$ and $\mathrm{C}-\mathrm{S}-\mathrm{H}$ in composite cement pastes containing high amounts of BFS. Cement and Concrete Research. 40, pp.284-92.

51. McCarthy, M.J. and Dhir, K. (2005) Development of high volume fly ash cements for use in concrete construction. Fuel. 84 (11), pp.1423-32.

52. Khatri, R., Sirivivatnanon, V. and Gross, W. (1995) Effect of different supplementary cementitious materials on mechanical properties of high performance concrete. Cement and Concrete Research. 25 (1), pp.209-20.

53. Younsi, A., Turcry, Ph., Aït-Mokhtar, A. and Staquet, S. (2013) Accelerated carbonation of concrete with high content of mineral additions: Effect of interactions between hydration and drying. Cement and Concrete Research. 43, pp.25-33.

54. Qiang, W., Peiyu, Y., Jianwei, Y. and Bo, Z. (2013) Influence of steel slag on mechanical properties and durability of concrete. Construction and Building Materials. 47, pp.1414-1420.

55. Teng, S., Lim, T.Y.D. and Divsholi, B.S. (2013) Durability and mechanical properties of high strength concrete incorporating ultra fine Ground Granulated Blast-furnace Slag. Construction and Building Materials. 40, pp.875-881.

56. Elahi, A., Basheer, P.A.M., Nanukuttan, S.V., Khan, Q.U.Z. (2010) Mechanical and durability properties of high performance concretes containing supplementary cementitious materials. Construction and Building Materials. 24, pp.292-99.

57. Ling, T.C., Poon, C.S. and Kou, S.C. (2012) Influence of recycled glass content and curing conditions on the properties of self-compacting concrete after exposure to elevated temperatures. Cement \& Concrete Composites. 34, pp.265-72.

58. Nikbin, I.M., Dehestani, M., Beygi, M.H.A. and Rezvani, M. (2014) Effects of cube size and placement direction on compressive strength of self-consolidating concrete. Construction and Building Materials. 59, pp.144-150.

59. Bhanja, S. and Sengupta, B. (2002) Investigations on the compressive strength of silica fume concrete using statistical methods. Cement and Concrete Research. 32 , pp.1391-94. 
60. Guneyisi, E., Gesoglu, M. and Ozbay, E. (2010) Strength and drying shrinkage properties of self-compacting concretes incorporating multi-system blended mineral admixtures. Construction and Building Materials. 24, pp.1878-1887.

61. Yliniemi, J., Nugteren, H., Illikainen, M., Tiainen, M. Weststrate, R. \& Niinimäki, J. (2016). Lightweight aggregates produced by granulation of peat-wood fly ash with alkali activator. International Journal of Mineral Processing, 149, pp.42-49.

62. Colangelo, F., Messina, F. \& Cioffi, R. (2015) Recycling of MSWI fly ash by means of cementitious double step cold bonding pelletization: technological assessment for the production of lightweight artificial aggregates. Journal of Hazardous Materials. 299, pp.181-91.

63. Ferone, C., Colangelo, F., lucolano, F., Liguori, B. \& Cioffi, R. (2013) Coal combustion wastes reuse in low energy artificial aggregates manufacturing. Materials, 6(11), pp.5000-15. 